\title{
Phenotypic Expression of Heterozygous Lipoprotein Lipase Deficiency in the Extended Pedigree of a Proband Homozygous for a Missense Mutation
}

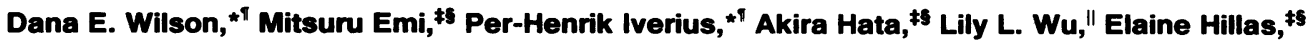 \\ Roger R. Williams, ${ }^{* 11}$ and Jean-Marc Lalouel $\$ \$$ \\ *Department of Internal Medicine, ${ }^{\ddagger}$ Department of Human Genetics, ${ }^{\S}$ Howard Hughes Medical Institute, \\ and "Cardiovascular Genetics Research Clinic, University of Utah Health Sciences Center, Salt Lake City, Utah 84132; \\ and 'the Veterans Affairs Medical Center, Salt Lake City, Utah 84148
}

\begin{abstract}
Familial lipoprotein lipase (LPL) deficiency is a rare genetic disorder accompanied by well-characterized manifestations. The phenotypic expression of heterozygous LPL deficiency has not been so clearly defined. We studied the pedigree of a proband known to be homozygous for a mutation resulting in nonfunctional LPL. Hybridization of DNA from 126 members with allele-specific probes detected 29 carriers of the mutant allele. Adipose tissue LPL activity, measured previously, was reduced by $50 \%$ in carriers, but did not reliably distinguish them from noncarriers. Carriers were prone to the expression of a form of familial hypertriglyceridemia characterized by increased plasma triglyceride, VLDL cholesterol and apolipoprotein B, and decreased LDL and HDL cholesterol concentrations. These manifestations were age modulated, with conspicuous differences between carriers and noncarriers observed only after age 40 . Several noncarriers exhibited similar lipid abnormalities, but without the inverse relationship between VLDL cholesterol and LDL cholesterol noted among carriers. In addition to age and carrier status, the potentially reversible conditions, obesity, hyperinsulinemia and lipid-raising drug use were contributory. Thus heterozygous lipoprotein lipase deficiency, together with age-related influences, may account for a form of familial hypertriglyceridemia. (J. Clin. Invest. 1990. 86:735-750.) Key words: lipoprotein lipase • chylomicron - genetics $\bullet$ VLDL $\cdot$ HDL
\end{abstract}

\section{Introduction}

Familial hyperchylomicronemia (type I hyperlipoproteinemia) is a rare inherited disease due to complete or near-complete deficiency of lipoprotein lipase (LPL), ${ }^{1}$ a triglyceride hydrolase responsible for the processing of the triglyceride-rich lipoproteins, chylomicrons, and VLDLs. Affected subjects classically present in infancy with fat intolerance, episodic ab-

Dr. Emi's present address is Department of Bioscience, National Cardiovascular Center Research Institute, Fujishiro-dai 5, Suita, Japan 565.

Address reprint requests to Dr. Dana E. Wilson, Endocrinology Section (111E), Veterans Administration Medical Center, 500 Foothill Boulevard, Salt Lake City, UT 84148.

Received for publication 6 February 1990 and in revised form 4 May 1990.

1. Abbreviations used in this paper: FCR, fractional catabolic rate; LPL, lipoprotein lipase.

The Journal of Clinical Investigation, Inc.

Volume 86, September 1990, 735-750 dominal pain with or without documented pancreatitis, eruptive xanthomatosis, severe hypertriglyceridemia, and fasting hyperchylomicronemia (1-3). A clinically similar disorder occurs with inherited deficiency of the LPL cofactor, apo C-II $(1,4)$.

The inheritance of familial hyperchylomicronemia is characterized by the absence of vertical transmission, multiple affected siblings, frequent consanguinity, and reduced LPL activities in parents (1-8). These findings imply that LPL-deficient probands are often homozygous for a mutant LPL allele. Relatives of reported probands have had variable lipoprotein patterns. Parents have had either increased VLDL alone or entirely normal lipids and lipoproteins (1). Other family members suspected of being heterozygous for a mutant LPL allele have been described with chylomicronemia and increased VLDL (type V), increased VLDL alone (type IV), increased LDL (type IIA), or increased VLDL and LDL (type IIB) $(7,9,10)$. Reduced HDL cholesterol concentrations have been observed regularly among hypertriglyceridemic relatives. These observations led to the suggestion $(6,7)$ that the phenotype resulting from the carrier genotype is familial combined hyperlipidemia (11).

Heterozygotes for LPL deficiency have escaped unambiguous identification. In obligate carriers mean adipose tissue LPL activities are reduced 50\% (5), but individual measurements overlap with normal (7). Suspected carriers likewise may have reduced or normal postheparin plasma LPL activities by selective assay (1). Babirak and co-workers (6) assayed immunoreactive LPL (12-14) along with postheparin plasma LPL activity to identify nonobligate carriers in small kindreds.

We previously described a patient with classical LPL deficiency (type I) along with data from 47 relatives in her large nonconsanguineous pedigree (7). When she was first studied at age 19, postheparin plasma and adipose tissue LPL activities were at the limits of detection. Apo C-II was present on polyacrylamide gel electrophoresis and normal LPL cofactor activity was detected (7). Plasma lipids and lipoproteins were entirely normal in the proband's father and the paternal lineage. Her mother had Type IV hyperlipoproteinemia, and some members of the maternal lineage exhibited hypertriglyceridemia, intermittent fasting chylomicronemia, elevated VLDL cholesterol, and/or decreased HDL cholesterol concentrations. Three individuals in the pedigree had calculated LDL cholesterol concentrations that exceeded 95th percentile age- and sex-specific cutoffs. Whether the multiple lipoprotein patterns observed in relatives of the proband resulted from heterozygous LPL deficiency or from the fortuitous, independent occurrence of a distinct familial condition could not be resolved in the absence of specific genetic markers.

Determination of the cDNA sequence for the normal human enzyme (15) and the structure of the human gene (16) 
opened the way for genetic characterization of probands with clinical LPL deficiency (16-18). By cloning and sequencing cDNA prepared from adipose tissue total RNA isolated in the proband, we have found that she was homozygous for a single point mutation (GGG $\rightarrow$ GAG) at position 818 of the LPL cDNA leading to a glycine-to-glutamic acid substitution at residue 188 of the mature enzyme (18). Furthermore, in vitro expression of the mutant gene resulted in the production of immunoreactive but functionally defective LPL (18). Profound deficiency of postheparin plasma LPL activity in the proband (7) was confirmed independently, and immunoreactive material was detected in postheparin plasma with a specific ELISA.

Knowing the molecular defect in the proband in the present study, it became possible to determine directly the carrier status of family members with respect to this mutation and to investigate phenotypic expression of the mutation in the heterozygous state.

\section{Methods}

Experimental subjects. K2003 is nonconsanguineous, Caucasian, and of mostly Northern European descent. Both of the proband's grandfathers died before age 65 with a history of heart disease. The maternal grandmother died at 82 of unknown causes. The paternal grandmother, 81 yr old at the time of our previous study, died in the interim. The proband's father has developed non-insulin-dependent diabetes mellitus. He received a pacemaker for cardiac arrhythmia in 1989 but he did not have significant coronary artery disease by angiography.

Most of the 47 family members originally ascertained between 1978 and 1981 consented to be restudied. Additional subjects from the extended pedigree, including spouses, were recruited randomly in the absence of information about their lipid or lipoprotein profiles, and initially without knowledge of parental or sibling carrier status. Later, as the carrier status of members of the pedigree became known, the offspring of carriers were actively recruited. In toto, 126 subjects were sampled, excluding the index patient. All subjects completed a targeted questionnaire, had body height, weight, and blood pressure measured, and gave informed consent according to institutional guidelines.

Laboratory analyses. Venous blood samples were collected after subjects had fasted 12-15 h according to Lipid Research Clinic guidelines (19). Plasma lipids were characterized by a microprocedure described elsewhere (20). The VLDL were separated from other lipoproteins by room temperature ultracentrifugation of $200 \mu$ l of plasma for 4 $\mathrm{h}$ at $60,000 \mathrm{rpm}$ in a tabletop centrifuge (model TL-100; Beckman Instruments, Fullerton, CA). Cholesterol in the HDL fraction was measured after $\mathrm{MgCl}_{2}$-dextran sulfate precipitation (21). LDL cholesterol was calculated as the difference between cholesterol in the ultracentrifugal bottom fraction and measured HDL cholesterol.

Uric acid, glucose, urea nitrogen, total bilirubin, albumin, calcium, total protein, phosphorous, creatinine, and electrolyte concentrations, and aspartate aminotransferase, lactate dehydrogenase, and $\gamma$-glutamyltransferase activities were determined with Baker reagents on an autoanalyzer (Encore II; Baker Instruments, Allentown, PA). Serum insulin was measured by RIA (Cambridge Medical Diagnostics, Billerica, MA). Adipose tissue lipoprotein lipase activities were assayed in 1981 as described in our published report (7).

Genomic DNA amplification and dot-blot hybridization. Two synthetic primers, LP790 (5'-GTAGACGTCTTACACACA-3') and RLP828 (5'-TGGATTCCAATGCTTCGA-3') were used to amplify enzymatically a 56-bp region (nucleotides 790-845) of the LPL gene. A reaction mixture containing $1 \mu \mathrm{g}$ of genomic DNA was denatured at $95^{\circ} \mathrm{C}$ for $1 \mathrm{~min}$, primer annealed at $60^{\circ} \mathrm{C}$ for $30 \mathrm{~s}$, and extended at $72^{\circ} \mathrm{C}$ for $1 \mathrm{~min}$ for a total of 30 cycles. Cloned M13 DNA samples containing the normal and mutant LPL sequences were treated identically and used as controls for hybridization in every run. Amplified
DNA (10 ng) was spotted on nylon membranes and hybridized with ${ }^{32} \mathrm{P}$-end-labeled oligonucleotide probes $\left(818 \mathrm{G}, 5^{\prime}\right.$-CCAGGGGACCCTCTGGTGA-3' or 818A, 5'-TCACCAGAGAGTCCCCTGG-3') corresponding respectively to normal and mutant sequences. The membranes were washed at $62^{\circ} \mathrm{C}$ and autoradiographed (18).

Data analysis. Statistical analyses were carried out using standard methods $(22,23)$. Raw data were age- and sex-adjusted (11) when appropriate to male age 40-44 values, using data from Visit 2 in the Lipid Research Clinics tables (24). The Mann-Whitney U test was used to compare independent two-sample cases and Kendall's rank correlation, $\tau$, was used for correlation analysis unless skewed data were first normalized by log-transformation so that parametric correlations could be carried out. One insulin-treated diabetic noncarrier (no. 415) with a measured serum insulin value of $253 \mu \mathrm{U} / \mathrm{ml}$, presumed to be the result of interfering antiinsulin antibodies, was excluded from comparisons that included serum insulin concentration. Multiple linear regression and discriminant analyses were carried out with SPSS/PC+ statistical software (SPSS Inc., Chicago, IL).

\section{Results}

126 subjects were studied, 76 females and 50 males (Fig. 1 and Appendix). 29 heterozygous carriers were detected unambiguously by dot-blot hybridization using allele-specific oligonucleotide probes, with mutant and wild-type sequence controls in every test (18). Females were overrepresented proportionately among both carriers and noncarriers, ostensibly because inflexible employment schedules hindered recruitment of males.

Plasma lipids, lipoproteins, and apolipoproteins. In carriers, triglyceride concentrations were skewed toward higher values (Fig. 2) and were significantly increased compared to non-carriers (Table I, all subjects). Carriers also had increased VLDL cholesterol and tended to have higher total plasma apoB concentrations $(P=0.062)$. This reflected an increase in VLDL-associated apoB since there was a significant positive correlation of total apoB with VLDL cholesterol $(P=0.0001$ by Mann-Whitney; $r=0.659$ by parametric analysis) but not with LDL cholesterol. HDL cholesterol concentrations were skewed toward lower values in carriers (Fig. 3) and were significantly decreased. ApoA-I concentrations however did not differ significantly between the two groups so the HDL cholesterol/apoA-I ratio tended to be lower in carriers $(P=0.062)$.

Effect of age on plasma lipids and lipoproteins. The relationship between genotype, age, and log-normalized plasma triglyceride concentration was examined since the expression of familial hypertriglyceridemia is often delayed until middle age (25). As observed by others $(24,26)$, triglyceride concentrations rose with age both in noncarriers and carriers (Fig. 4) as did VLDL cholesterol (data not shown). Before age 40 there were no statistically significant differences in lipid, lipoprotein, or apolipoprotein concentrations between normals and carriers (Table I). In contrast, individuals age $\mathbf{4 0}$ and older with heterozygous LPL deficiency had significantly increased plasma triglyceride, VLDL cholesterol and apoB concentrations, and decreased HDL cholesterol concentrations. The ratio, HDL cholesterol/apoA-I, was reduced in older carriers $(P=0.036)$, consistent with relative triglyceride enrichment of HDL without a change in particle number.

The age dependency of phenotypic expression was tested rigorously using log-transformed-dependent variables. After ruling out an independent interaction between age and sex by analysis of noncarriers only (data not shown), a correlation matrix between dependent and predictor variables was gener- 


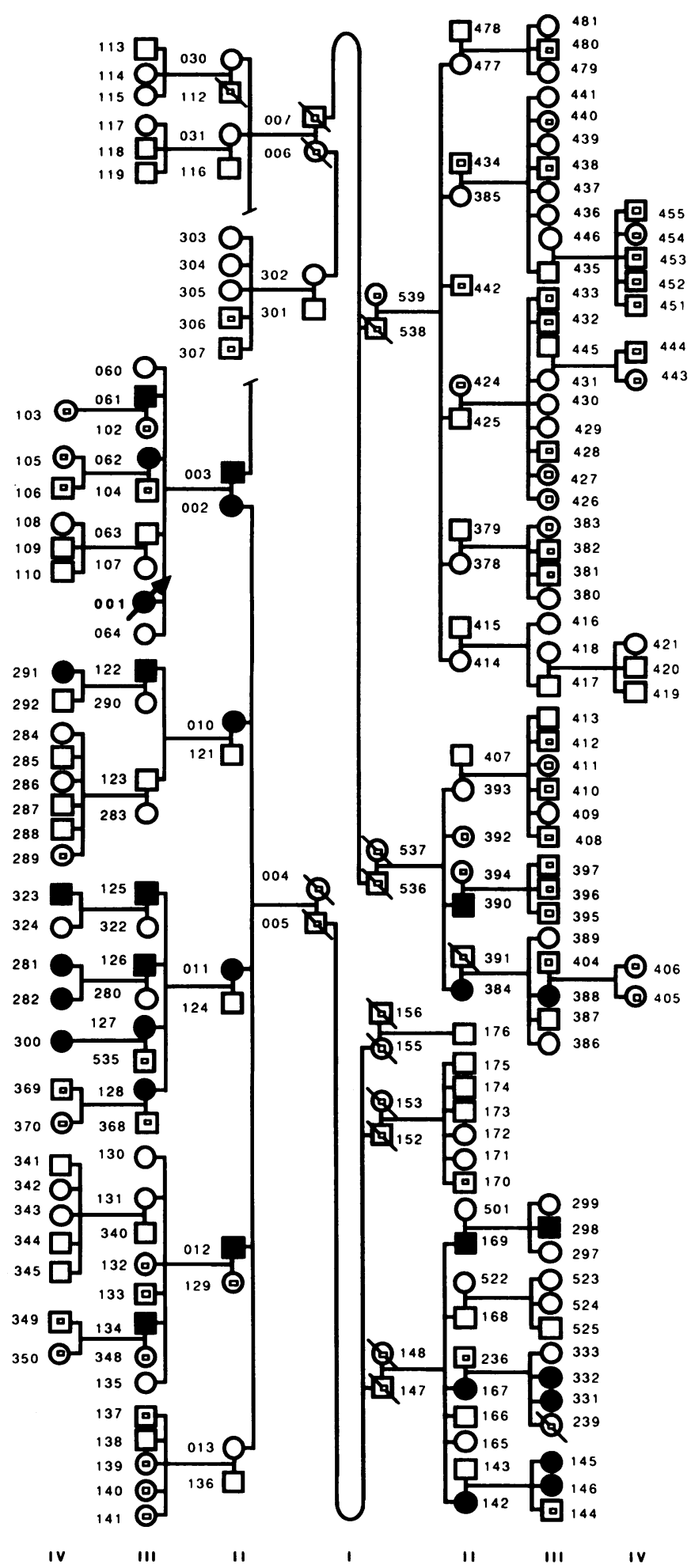

Figure 1. Kindred 2003. The proband (001) is indicated by an arrow. -, subject proven to be a carrier with allele-specific oligonucleotide probes; $\bigcirc$, noncarrier; $\odot$, living subject, not studied; $₫$, deceased subject, not studied.

ated using data from all subjects (Table II). As expected, strongly significant positive correlations were seen between age and In (triglyceride), In (VLDL cholesterol), In (LDL cholesterol), and In (apolipoprotein B).
A multivariate linear model was then used to test the contributions of age, sex, carrier status, age-carrier status (the product of age and coded carrier status), and other candidate variables. This analysis showed an independent contribution of age-carrier status to VLDL concentration, reflected by significant positive correlations with ln (triglyceride), ln (VLDL cholesterol), and In (apolipoprotein B), as well as a negative correlation with HDL cholesterol but not apoA-I concentrations (Table III). The highly significant correlations observed between age-carrier status and the dependent variables confirmed the potentiating effect of age on expression of the mutant allele.

$L D L$ cholesterol in carriers. If heterozygous LPL deficiency were expressed in the pedigree as familial combined hyperlipidemia $(6,7)$, LDL cholesterol concentrations ought to be significantly elevated in some proven carriers. However, no significant correlation between carrier status and LDL cholesterol was observed in the multivariate analysis (Table III). In fact, LDL cholesterol was significantly lower in carriers than in non-carriers after the age of 40 (Table I; $P=0.009$ ). In our previous report (7) three individuals had LDL cholesterol concentrations that exceeded age- and sex-specific 95 th percentile cutpoints. The first (numbered III-10 in reference 7, current pedigree 133) with an LDL cholesterol of $202 \mathrm{mg} / \mathrm{dl}$ in 1979 and a 50\% likelihood of carrying the mutation, could not be restudied. This individual may have inherited hypercholesterolemia from his mother, a noncarrier spouse unrelated to the
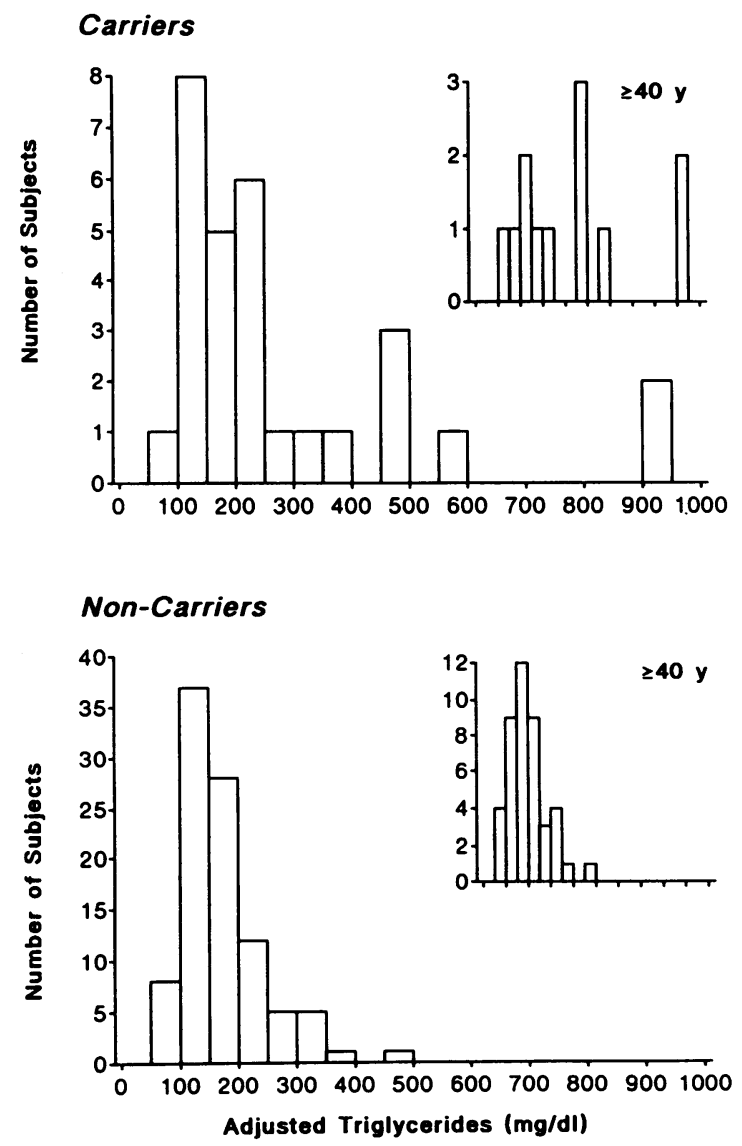

Figure 2. Histograms of age- and sex-adjusted $(11,35)$ plasma triglyceride concentration in carriers $(n=97)$ and noncarriers $(n=29)$. (Inset) Subjects age 40 or older. 
Table I. Age- and Sex-adjusted Lipid and Lipoprotein Variables in Carriers and Noncarriers Stratified by Age

\begin{tabular}{|c|c|c|c|c|c|}
\hline & \multicolumn{2}{|c|}{ Noncarriers } & \multicolumn{2}{|c|}{ Carriers } & \multirow[b]{2}{*}{$P$ value* } \\
\hline & Mean & SD & Mean & SD & \\
\hline All subjects $(n=126)$ & \multicolumn{2}{|c|}{$n=96$} & \multicolumn{2}{|c|}{$n=29$} & \\
\hline Triglyceride & 169 & 73 & 282 & 41 & 0.005 \\
\hline Total cholesterol & 211 & 31 & 224 & 45 & - \\
\hline VLDL cholesterol & 33.5 & 17.0 & 55.7 & 39.8 & 0.007 \\
\hline LDL cholesterol & 139 & 28 & 130 & 39 & - \\
\hline HDL cholesterol & 36.9 & 10.9 & 31.1 & 11.8 & 0.02 \\
\hline Apolipoprotein B & 72.0 & 21.0 & 82.0 & 28.6 & 0.06 \\
\hline Apolipoprotein A-I & 131 & 24 & 126 & 21 & - \\
\hline TG/VLDL cholesterol & 5.2 & 1.2 & 5.3 & 1.1 & - \\
\hline HDL cholesterol/ApoA-I & .285 & .088 & .248 & .089 & 0.06 \\
\hline LDL/HDL cholesterol & 4.14 & 1.61 & 4.80 & 2.29 & - \\
\hline Age $<40 \mathrm{yr}(n=71)$ & \multicolumn{2}{|c|}{$n=54$} & \multicolumn{2}{|c|}{$n=17$} & \\
\hline Triglyceride & 149 & 50 & 170 & 66 & - \\
\hline Total cholesterol & 209 & 27 & 212 & 27 & - \\
\hline VLDL cholesterol & 28.0 & 10.1 & 31.8 & 10.2 & - \\
\hline LDL cholesterol & 141 & 25 & 145 & 30 & - \\
\hline HDL cholesterol & 37.7 & 9.3 & 34.5 & 10.3 & - \\
\hline Apolipoprotein B & 62.4 & 16.1 & 66.9 & 12.8 & - \\
\hline Apolipoprotein A-I & 132 & 24 & 122 & 18 & - \\
\hline TG/VLDL cholesterol & 5.4 & 0.9 & 5.4 & 0.8 & - \\
\hline HDL cholesterol/ApoA-I & .288 & .066 & .280 & .075 & - \\
\hline LDL/HDL cholesterol & 4.00 & 1.28 & 4.56 & 1.49 & - \\
\hline Age $\geq 40$ yr $(n=55)$ & \multicolumn{2}{|c|}{$n=42$} & \multicolumn{2}{|c|}{$n=12$} & \\
\hline Triglyceride & 195 & 88 & 441 & 267 & 0.0003 \\
\hline Total cholesterol & 213 & 37 & 240 & 61 & - \\
\hline VLDL cholesterol & 40.5 & 21.0 & 89.6 & 41.7 & 0.0003 \\
\hline LDL cholesterol & 136 & 31 & 110 & 42 & 0.009 \\
\hline HDL cholesterol & 35.8 & 12.6 & 26.3 & 12.7 & 0.04 \\
\hline Apolipoprotein B & 84.4 & 20.2 & 103 & 31.6 & 0.03 \\
\hline Apolipoprotein A-I & 130 & 26 & 131 & 24 & - \\
\hline TG/VLDL cholesterol & 5.1 & 1.3 & 5.0 & 1.6 & - \\
\hline HDL cholesterol/ApoA-I & .281 & .111 & .202 & .090 & 0.04 \\
\hline LDL/HDL cholesterol & 4.32 & 1.95 & 5.28 & 3.11 & - \\
\hline
\end{tabular}

Lipid and lipoprotein variables were normalized to male sex at age 40 by adding or subtracting age- and sex-specific differences taken from the Lipid Research Clinics database (24). Concentrations are expressed in milligrams/deciliter. ${ }^{*}$ Significance levels for differences in means between the two groups were obtained by the Mann-Whitney $\mathrm{U}$ test corrected for ties.

proband, whose total cholesterol was 256 and calculated LDL was $163 \mathrm{mg} / \mathrm{dl}$. The second (III-5, 125) a proven carrier, had an LDL cholesterol of $172 \mathrm{mg} / \mathrm{dl}$ (75-90th percentile) on retesting. The third (III-22, 138), with an LDL cholesterol of 137 $\mathrm{mg} / \mathrm{dl}$ when first seen at age 12 , proved to be a noncarrier. Although in the present study, two normotriglyceridemic carriers had LDL cholesterol concentrations exceeding 95th percentile population-based cutpoints, the prevalence of elevated values was not different between carriers and noncarrier pedigree controls exposed to similar environmental and background genetic influences (Table IV). Moreover, all carriers whose plasma triglyceride concentrations exceeded the 90th percentile had normal or decreased LDL cholesterol concen- trations. Thus heterozygous LPL deficiency in this pedigree was expressed as familial hypertriglyceridemia.

$L D L$ and HDL cholesterol in hypertriglyceridemia. The relationships between HDL or LDL cholesterol and plasma triglyceride or VLDL cholesterol concentrations were explored in estrogen nonusers using log-normalized age- and sex-adjusted values. HDL cholesterol decreased as VLDL cholesterol (Fig. 5) or triglyceride (analysis not shown) concentrations increased, with similar regression slopes in both carriers and noncarriers. In contrast, LDL cholesterol fell with rising plasma VLDL cholesterol (Fig. 6) or triglyceride (analysis not shown) concentrations in carriers but failed to do so in noncarriers.

An LDL/HDL ratio of 5 or greater was present in $24 \%$ of carriers and $22 \%$ of noncarriers. Although there was no statistically significant difference in the means (Table I), the LDL/ HDL ratio was affected differently in carriers and noncarriers. With increasing plasma triglyceride concentration the LDL/ HDL ratio rose significantly in noncarriers $(r=0.456 ; P$ $=0.0001)$ but failed to increase in carriers $(r=0.126 ; P$ $=0.52$ ). This difference reflected the tendency for LDL and HDL to decrease proportionately in carriers.

Drug and gender effects. The use of drugs known to be associated with or to provoke hyperlipidemia in susceptible individuals is shown in Table V. There was modest overrepresentation of estrogen-treated women among noncarriers, whereas the prevalence of lipid-raising antihypertensive ther-

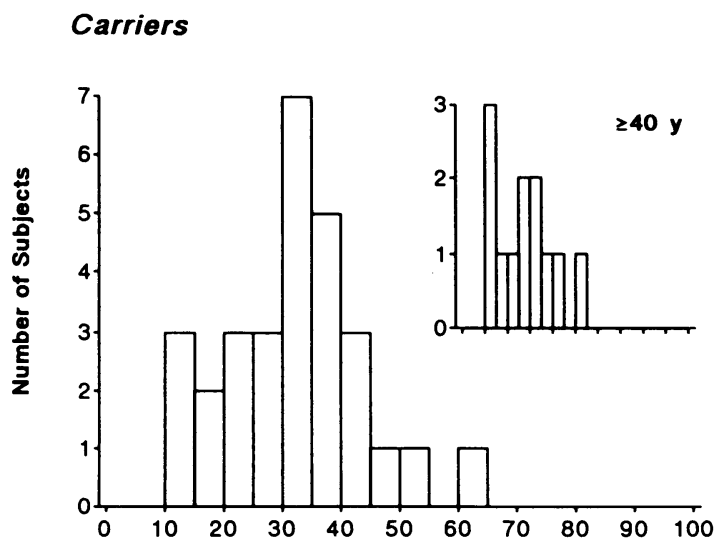

Non-Carriers

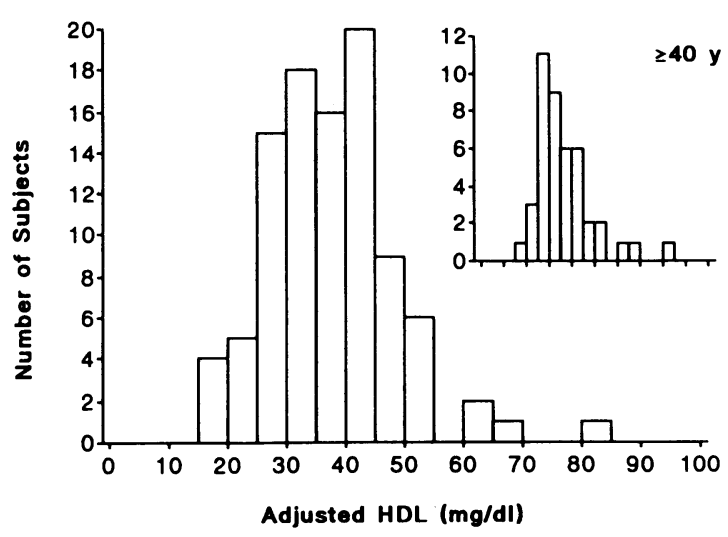

Figure 3. Histograms of age- and sex-adjusted HDL cholesterol concentration in carriers and noncarriers. (Inset) Subjects age 40 or older. 

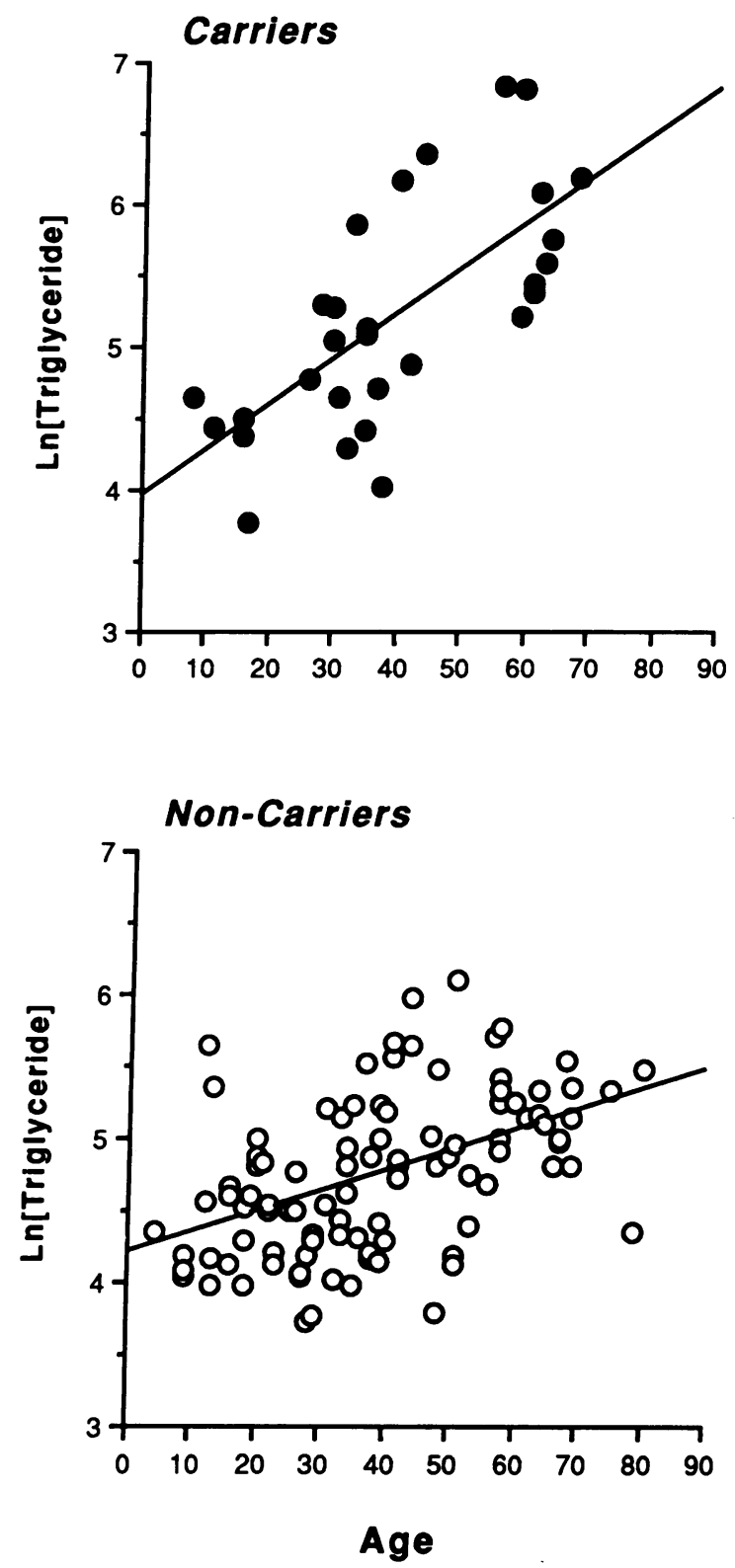

Figure 4. Linear regression of log-normalized plasma triglyceride concentration on age for carriers and noncarriers. Pearson correlation coefficients for noncarriers $(r=0.686 ; P=0.0001)$ and carriers $(r=0.47 ; P=0.001)$ were calculated for all subjects. apy was greater among carriers. The overall incidence of tobacco and alcohol use was low. Although $\beta$-blocker and alcohol use (modest in all cases) were more frequent among the carriers, noncarriers and carriers were well matched in other respects.

In the multivariate analysis (Table III), there were positive correlations between variables reflecting HDL concentration (In [HDL cholesterol] and In [apolipoprotein A-I]) and female gender or estrogen use. Although thiazides and $\beta$-blockers appeared to have modest effects on lipid variables (Table II) most of these associations disappeared in the multivariate analysis (Table III). Thus, neither alcohol nor antihypertensive use could account for the observed differences between carriers and noncarriers.

Obesity and related conditions. Familial hypertriglyceridemia with or without fasting chylomicronemia is often associated with obesity, hypertension, hyperglycemia, hyperinsulinemia, and hyperuricemia $(25,27,28)$. It is not known whether these associations are genetically determined, or due to lifestyle and environmental factors. Of the eight instances of non-insulin-dependent diabetes, six occurred in noncarriers and 2 (003 and 384) among carriers (Appendix and Table V). Thus, the prevalence of hyperglycemia and overt diabetes was no different between carriers and noncarriers, nor increased from the known prevalence of diabetes in the general population.

No statistically significant differences were found by univariate analysis between noncarriers and carriers in mean age, blood glucose, serum insulin, or body mass index (Table VI). However, serum uric acid was increased $(P=0.018)$ and blood pressure tended to be higher in older carriers. Hypertriglyceridemic carriers and noncarriers were older, more obese, more hyperglycemic, hyperinsulinemic, hyperuricemic, and hypertensive than normotriglyceridemic subjects of the same genotype (Table VII). As expected, these variables proved highly interdependent. Plasma insulin concentration rose with increasing body mass index both in normals and carriers $(P$ $=0.0001$ and $P=0.0005$, respectively; Kendall's $\tau$ corrected for ties). Similarly plasma triglyceride concentration correlated with body mass index $(P=0.0001$ and $P=0.001$; analyses not shown) and with plasma insulin $(P=0.0001$ and 0.003$)$ in noncarriers and carriers, respectively (Fig. 7). Weaker negative correlations were also found between HDL cholesterol and plasma insulin or body mass index $(P=0.02-0.05$; analyses not shown). Thus, conditions previously shown to be associated with familial hypertriglyceridemia were also associated

Table II. Correlation Matrix for Lipids and Lipoproteins and Potential Predictor Variables

\begin{tabular}{|c|c|c|c|c|c|c|c|c|}
\hline & Age & Sex* & Carrier status* & Age $\cdot$ Carrier status ${ }^{\ddagger}$ & Body mass index & Estrogen use* & Thiazide use* & $\beta$-Blocker use* \\
\hline Ln (Triglyceride) & $0.50^{\S}$ & -0.17 & $0.29^{\S}$ & $0.45^{\S}$ & $0.42^{\S}$ & 0.09 & $0.22^{\prime \prime}$ & $0.26^{\prime \prime}$ \\
\hline Ln (VLDL cholesterol) & $0.51^{\S}$ & -0.12 & $0.30^{\S}$ & $0.45^{\S}$ & $0.34^{\S}$ & 0.09 & 0.17 & $0.24^{9}$ \\
\hline Ln (LDL cholesterol) & $0.38^{\S}$ & 0.11 & -0.07 & -0.06 & 0.17 & -0.10 & -0.05 & -0.02 \\
\hline Ln (HDL cholesterol) & -0.02 & $0.38^{\S}$ & $-0.26^{\prime}$ & $-0.28^{\S}$ & -0.09 & $0.29^{\S}$ & -0.07 & -0.13 \\
\hline Ln (Apolipoprotein B) & $0.59^{\S}$ & -0.05 & 0.17 & $0.33^{\S}$ & $0.41^{\S}$ & 0.03 & $0.21^{11}$ & $0.24^{\prime}$ \\
\hline Ln (Apolipoprotein A-I) & -0.03 & $0.46^{\S}$ & -0.09 & -0.06 & -0.10 & $0.41^{\S}$ & 0.05 & -0.05 \\
\hline
\end{tabular}

Log-transformed unadjusted raw data for all subjects were used. Pearson correlation coefficients were calculated after pairwise exclusion of missing values. ${ }^{*}$ Numerical coding: sex (male $=0$; female $=1$ ); Carrier status (noncarrier $=0$; carrier $=1$ ); estrogen, thiazide, and $\beta$-blocker use (nonuser $=0$; user $=1$ ). ${ }^{\ddagger}$ The variable age $\cdot$ carrier status was computed as the product of age and carrier status. Alcohol use was not significantly associated with any of the lipid or lipoprotein variables. ${ }^{\S} P \leq 0.001$; $^{\prime \prime} P \leq 0.05$; $^{\prime} P \leq 0.01$ (two-tailed significance). 
Table III. Multiple Linear Regression Analysis of Predictor Variables for Lipid and Lipoprotein Parameters

\begin{tabular}{|c|c|c|c|c|c|}
\hline Dependent variable & $\begin{array}{l}\text { Retained predictor } \\
\text { variables* }\end{array}$ & $p$ & $r$ & $F$ & $P$ value \\
\hline \multirow[t]{4}{*}{ Ln (Triglyceride) } & Age & 0.32 & & & 0.0002 \\
\hline & Age $\cdot$ Carrier status & 0.35 & & & 0.0001 \\
\hline & Body mass index & 0.21 & & & 0.01 \\
\hline & All variables & & 0.64 & 27.6 & $<0.0001$ \\
\hline \multirow[t]{3}{*}{ Ln (VLDL cholesterol) } & Age & 0.43 & & & $<0.0001$ \\
\hline & Age $\cdot$ Carrier status & 0.36 & & & $<0.0001$ \\
\hline & All variables & & 0.62 & 37.2 & $<0.0001$ \\
\hline \multirow[t]{3}{*}{ Ln (LDL cholesterol) } & Age & 0.45 & & & $<0.0001$ \\
\hline & Thiazide use & -0.19 & & & 0.03 \\
\hline & All variables & & 0.43 & 13.4 & $<0.0001$ \\
\hline \multirow{4}{*}{ Ln (HDL cholesterol) } & Sex & 0.31 & & & 0.0003 \\
\hline & Age $\cdot$ Carrier status & -0.28 & & & 0.0006 \\
\hline & Estrogen use & 0.18 & & & 0.04 \\
\hline & All variables & & 0.50 & 13.2 & $<0.0001$ \\
\hline \multirow[t]{3}{*}{ Ln (Apolipoprotein B) } & Age & 0.54 & & & $<0.0001$ \\
\hline & Age $\cdot$ Carrier status & 0.21 & & & 0.004 \\
\hline & All variables & & 0.63 & 38.8 & $<0.0001$ \\
\hline \multirow[t]{3}{*}{ Ln (Apolipoprotein A-I) } & Sex & 0.36 & & & $<0.0001$ \\
\hline & Estrogen use & 0.28 & & & 0.0008 \\
\hline & All variables & & 0.53 & 23.9 & $<0.0001$ \\
\hline
\end{tabular}

* Numerical coding is as indicated in Table II. $p$, partial correlation coefficient; $r$, multiple correlation coefficient; $F, F$-statistic; $P$ value, probability for $t$ statistic (partial correlations) or $F$-statistic. The predictor variables listed in Table II were tested by the stepwise procedure using default selection and exclusion criteria. A positive correlation with sex indicates higher HDL levels in females since the numerical code used for females was higher than that for males. Missing values were excluded pairwise.

with the expression of heterozygous LPL deficiency in this pedigree.

Separate multivariate analyses with the candidate variables showed systolic and diastolic blood pressure and uric acid to be associated with age and body mass index (Table VIII). Serum insulin concentration was associated with body mass index alone. A marginally significant independent contribution of age $\cdot$ carrier status to systolic blood pressure was observed even though subjects were receiving concurrent antihypertensive treatment. Although the latter observation might suggest that the mutant allele predisposes to hypertension, this conclusion is highly tentative since the number of affected carriers was small.

To further illustrate phenotypic differences between noncarriers and carriers, discriminant analysis was performed using carrier status as the grouping variable (Table IX). The discriminating variables chosen for testing were the plasma lipid and lipoprotein variables as well as other variables that might vary with carrier status. In the analysis, the strongest predictor of carrier status was plasma triglyceride concentration, followed by LDL cholesterol, and apoB. These three variables, which ostensibly reflect unique features of lipoprotein metabolism in the heterozygous state, correctly predicted carrier status in $83 \%$ of all analyzed cases.

Adipose tissue LPL activity. Knowledge of the LPL genotype in 14 ( 7 carriers and 7 noncarriers) of the 19 subjects previously studied in 1981 (7) permitted retrospective analysis of the ability of adipose tissue LPL activity to discriminate between carriers and noncarriers (Fig. 8). Mean activity was reduced $50 \%$ in carriers $(0.60 \pm 0.12$ vs. $1.21 \pm 0.18 \mathrm{nmol}$ of free fatty acid released/mg tissue per h; means \pm SEM; $P=0.02$ by either Mann-Whitney U or two-tailed $t$ test). However, overlap in values confirmed that measurement of adipose tissue LPL activity alone did not reliably distinguish heterozygous from normal individuals.

\section{Discussion}

We have studied the extended pedigree of a proband with type I hyperlipoproteinemia shown to be homozygous for a missense mutation in the lipoprotein lipase gene. This pedigree, notable for its size and lack of consanguinity as well as a low incidence of premature coronary artery disease and confounding variables such as alcohol abuse or tobacco use in living members (Table V), provided a unique opportunity to clarify the phenotype associated with heterozygous LPL deficiency. Carriers and noncarriers were identified by hybridization of enzymatically amplified DNA with allele-specific oligonucleotide probes. Genotyping proved essential since adipose tissue LPL activities, determined in a previous study (7) and examined retrospectively, did not detect proven carriers reliably.

The phenotype associated with heterozygous LPL deficiency in this pedigree was characterized by hypertriglyceridemia, elevated VLDL cholesterol, and low LDL and HDL cholesterol concentrations (type IV hyperlipoproteinemia), occurred together with well-recognized predisposing factors, and was transmitted in an autosomal codominant pattern. Hypertriglyceridemia in carriers proved to be strongly age dependent. Variable expression associated with age or age-related factors resulted in incomplete penetrance. Only $40 \%$ of proven carriers exhibited the abnormal phenotype. Thus, $94 \%$ of young carriers had normal triglyceride concentrations, 
Table IV. Prevalence of Abnormal Lipid and Lipoprotein Concentrations among Carriers and Noncarriers

\begin{tabular}{|c|c|c|c|c|c|c|c|}
\hline \multirow[t]{2}{*}{ Group } & \multirow[t]{2}{*}{ Carrier status } & \multicolumn{2}{|c|}{$\geq 90$ th percentile* } & \multirow[t]{2}{*}{$P$ value $^{\ddagger}$} & \multicolumn{2}{|c|}{$\geq 95$ th percentile } & \multirow[t]{2}{*}{$P$ value } \\
\hline & & $\%$ & $n$ & & $\%$ & $n$ & \\
\hline \multicolumn{8}{|l|}{ Total cholesterol } \\
\hline \multirow[t]{2}{*}{ All subjects (126) } & Noncarriers (97) & 13.4 & (13) & & 8.2 & (8) & \\
\hline & Carriers (29) & 17.2 & (5) & - & 10.3 & (3) & - \\
\hline \multirow[t]{2}{*}{ Age $<40 \mathrm{yr}(71)$} & Noncarriers (54) & 7.4 & (4) & & 3.7 & (2) & \\
\hline & Carriers (17) & 11.8 & (2) & - & 0.0 & (0) & - \\
\hline \multirow[t]{2}{*}{ Age $\geq 40 \mathrm{yr}(55)$} & Noncarriers (43) & 20.9 & (9) & & 14.0 & (6) & \\
\hline & Carriers (12) & 25.0 & (3) & - & 25.0 & (3) & - \\
\hline \multicolumn{8}{|l|}{ LDL cholesterol } \\
\hline \multirow[t]{2}{*}{ All subjects (126) } & Noncarriers (97) & 10.3 & $(10)$ & & 7.2 & (7) & \\
\hline & Carriers (29) & 10.3 & (3) & - & 6.9 & (2) & - \\
\hline \multirow[t]{2}{*}{ Age $<40$ yr $(71)$} & Noncarriers (54) & 11.1 & (6) & & 7.4 & (4) & \\
\hline & Carriers (17) & 11.8 & (2) & - & 5.9 & (1) & - \\
\hline \multirow[t]{2}{*}{ Age $\geq 40 \mathrm{yr}(55)$} & Noncarriers (43) & 9.3 & (4) & & 7.0 & (3) & \\
\hline & Carriers (12) & 8.3 & (1) & - & 8.3 & (1) & - \\
\hline \multicolumn{8}{|l|}{ Triglycerides } \\
\hline \multirow[t]{2}{*}{ All subjects (126) } & Noncarriers (97) & 12.4 & (12) & & 6.2 & (6) & \\
\hline & Carriers (29) & 31.0 & (9) & 0.04 & 27.6 & (8) & 0.008 \\
\hline \multirow[t]{2}{*}{ Age $<40 \mathrm{yr}(71)$} & Noncarriers (54) & 5.6 & (3) & & 1.9 & (1) & \\
\hline & Carriers (17) & 5.9 & (1) & 一 & 5.9 & (1) & - \\
\hline \multirow[t]{2}{*}{ Age $\geq 40 \mathrm{yr}(55)$} & Noncarriers (43) & 20.9 & (9) & & 11.6 & $(5)$ & \\
\hline & Carriers (12) & 66.7 & $(8)$ & 0.03 & 58.3 & (7) & 0.01 \\
\hline \multicolumn{8}{|l|}{ VLDL cholesterol } \\
\hline \multirow[t]{2}{*}{ All subjects (126) } & Noncarriers (97) & 20.6 & $(20)$ & & 8.2 & $(8)$ & \\
\hline & Carriers (29) & 44.8 & (13) & 0.03 & 34.5 & (10) & 0.005 \\
\hline \multirow[t]{2}{*}{ Age $<40 \mathrm{yr}(71)$} & Noncarriers (54) & 7.4 & (4) & & 3.7 & (2) & \\
\hline & Carriers (17) & 17.6 & (3) & - & 0.0 & $(0)$ & - \\
\hline \multirow[t]{2}{*}{ Age $\geq 40$ yr (55) } & Noncarriers (43) & 37.2 & (16) & & 14.0 & (6) & \\
\hline & Carriers (12) & 83.3 & $(10)$ & - & 83.3 & (10) & 0.004 \\
\hline \multirow[t]{2}{*}{ Group } & Carrier status & \multicolumn{2}{|c|}{$\leq 10$ th percentile* } & $P$ value ${ }^{\ddagger}$ & \multicolumn{2}{|c|}{$\leq 5$ th percentile } & $P$ value \\
\hline & & $\%$ & $n$ & & $\%$ & $n$ & \\
\hline \multicolumn{8}{|l|}{ HDL cholesterol } \\
\hline All subjects (126) & Noncarriers (97) & 30.9 & $(30)$ & & 16.5 & (16) & \\
\hline & Carriers (29) & 44.8 & (13) & - & 37.9 & (11) & 0.03 \\
\hline Age $<40$ yr $(71)$ & Noncarriers (54) & 20.4 & (11) & & 14.8 & $(8)$ & \\
\hline & Carriers (17) & 35.3 & (6) & - & 23.5 & (4) & - \\
\hline Age $\geq 40$ yr (55) & Noncarriers (43) & 44.2 & (19) & & 18.6 & (8) & \\
\hline & Carriers (12) & 58.3 & (7) & - & 58.3 & (7) & 0.04 \\
\hline
\end{tabular}

Prevalence of abnormal values for age- and sex-corrected lipid and lipoprotein variables shown as percent of total number of individuals in each group with number of individuals in parentheses. * Cutpoints $(\geq 90$ th and 95 th percentiles for total, LDL, and VLDL cholesterol and triglyceride concentrations, and $\leq 10$ th and 5th percentile cutpoints for HDL cholesterol) were taken from the Lipid Research Clinics Database (24). ${ }^{\ddagger}$ Levels of significance were estimated by Fisher’s Exact Test.

whereas two-thirds of older carriers were hypertriglyceridemic, with plasma triglyceride concentrations in the upper decile (24). Although the statistically significant associations between selected variables and age in our cross-sectional sample point to an effect of aging itself (26), secular differences between older and younger subjects cannot be entirely ruled out.

In our previous study of this kindred three subjects had elevated LDL cholesterol values. Lacking specific markers to identify carriers, we concluded that the phenotype in the pedigree resembled familial combined hyperlipidemia. In the present study, the prevalence of increased LDL cholesterol in proven carriers and noncarriers could be compared rigorously. Elevated LDL cholesterol concentrations were no more common among carriers than pedigree controls, nor more frequent than predicted from the distribution of LDL cholesterol concentrations extant in the general population (24). Thus in this pedigree heterozygous LPL deficiency predisposes to familial hypertriglyceridemia rather than familial combined hyperlipidemia.

Although hypertriglyceridemia, low HDL, and low LDL segregated with the mutant allele, a number of noncarriers exhibited similar abnormalities. Phenotypic differences be- 


\section{Carriers}

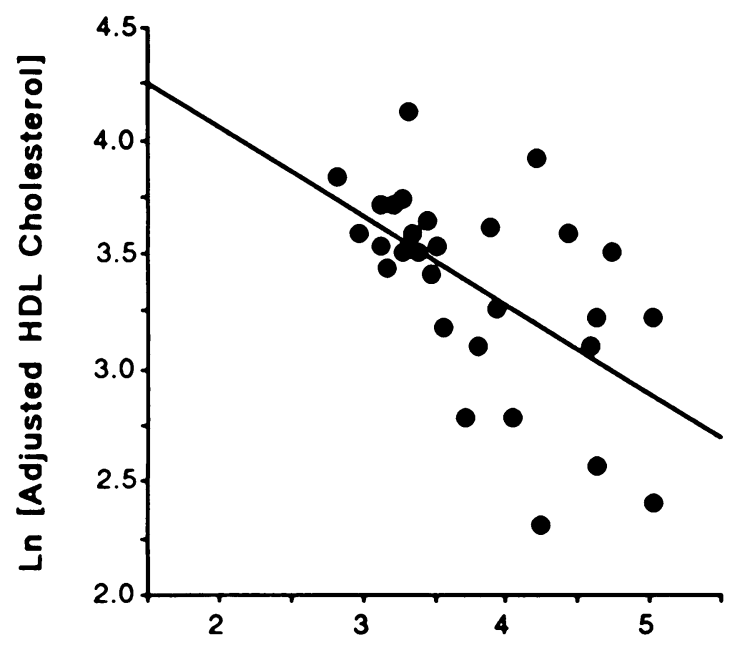

Non-Carriers

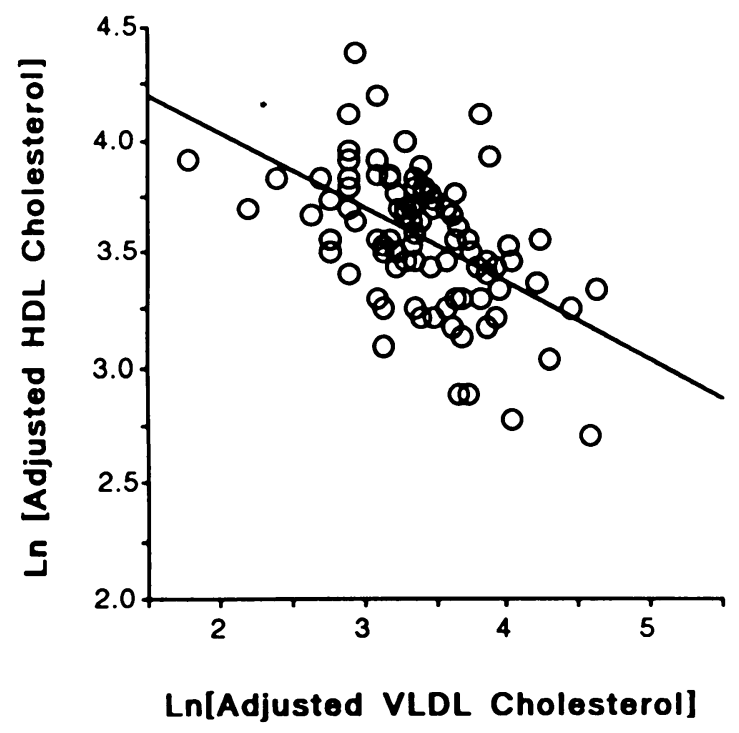

Figure 5. Linear regression of HDL cholesterol concentration on VLDL cholesterol concentration using log-normalized age- and sexadjusted values. Pearson correlation coefficients for carriers ( $r$ $=-0.57 ; P=0.003 ; n=24)$ and noncarriers $(r=-0.60 ; P$

$=0.0001 ; n=79$ ) were calculated after excluding estrogen users.

tween carriers and noncarriers were subtle. Decreased HDL cholesterol, a regular finding in hypertriglyceridemia of any cause (29), was present in both hypertriglyceridemic carriers and noncarriers in this study but was more pronounced in the former (Table I). These observations are consistent with a defect in LPL function in vivo since the plasma concentration of HDL cholesterol correlates directly with LPL activity and with fractional catabolic rate (FCR) of triglyceride or VLDL (30). Although apo A-I and A-II turnovers are increased in hypertriglyceridemia (31), plasma apo A-I concentrations, quantitatively similar to reported values (32), did not differ between groups. Thus the HDL cholesterol/apo A-I ratio was significantly reduced in carriers suggesting that the composition, but not the number, of HDL particles is altered in heterozygous LPL deficiency.

In contrast to HDL cholesterol, which decreased with hypertriglyceridemia in both carriers and noncarriers, LDL cholesterol fell significantly in carriers only. Several mechanisms might be involved including reduced lipolytic conversion of VLDL to LDL, exchange of triglyceride for free cholesterol between VLDL and LDL, or a shift in the density distribution of triglyceride-enriched LDL particles (33). Whichever mechanism is responsible, the LDL/HDL ratio, used widely to predict atherogenic risk, was significantly correlated with plasma triglyceride concentration only in noncarriers.

\section{Carriers}

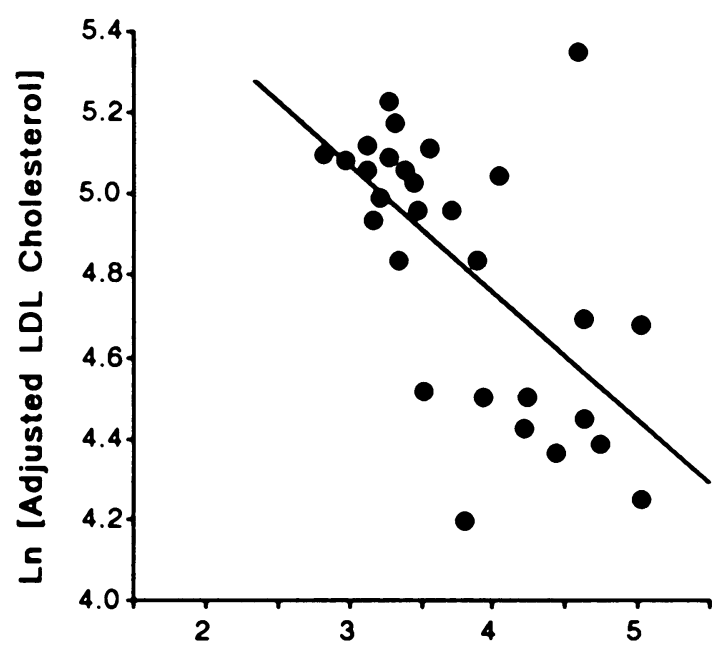

\section{Non-Carriers}

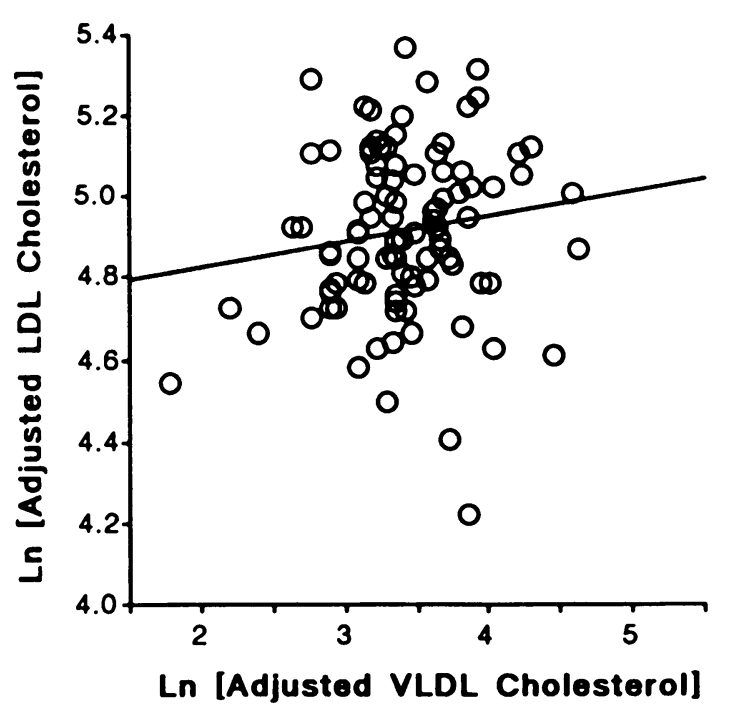

Figure 6. Linear regression of LDL cholesterol concentration on VLDL cholesterol concentration in individuals using log-normalized age- and sex-adjusted values. Pearson correlation coefficients for carriers $(r=-0.55 ; P=0.0005 ; n=24)$ and noncarriers $(r=0.13 ; P$ $=0.2 ; n=79)$ were calculated after excluding estrogen users. 
Table V. Prevalence of Medical Disorders, Drug Therapy, and Alcohol-Tobacco Use

\begin{tabular}{|c|c|c|c|c|c|c|c|}
\hline & \multicolumn{2}{|c|}{ All subjects } & \multicolumn{2}{|c|}{ Noncarriers } & \multicolumn{2}{|c|}{ Carriers } & \multirow[t]{2}{*}{$P$ value* } \\
\hline & $n$ & $\%$ & $n$ & $\%$ & $n$ & $\%$ & \\
\hline Hypertension & 27 & 21.4 & 19 & 19.6 & 8 & 27.6 & - \\
\hline Heart disease & 8 & 6.3 & 7 & 7.2 & 2 & 6.9 & - \\
\hline Gout & 2 & 1.6 & 1 & 1.0 & 1 & 3.4 & - \\
\hline \multicolumn{8}{|l|}{ Carbohydrate intolerance } \\
\hline Known diabetes & 8 & 6.3 & 6 & 6.2 & 2 & 6.9 & - \\
\hline Fasting glucose $115-139$ & 3 & 2.4 & 2 & 2.1 & 1 & 3.4 & - \\
\hline Estrogen therapy $y^{*}$ & $21 / 76$ & 27.6 & $17 / 58$ & 29.3 & $4 / 18$ & 22.2 & - \\
\hline Age $<45$ yr & $11 / 53$ & 20.8 & $9 / 41$ & 22.0 & $2 / 12$ & 16.7 & - \\
\hline Age $\geq 45 \mathrm{yr}$ & $10 / 23$ & 43.5 & $8 / 17$ & 47.1 & - $2 / 6$ & 33.3 & - \\
\hline Antihypertensive therapy & 19 & 15.1 & 12 & 12.4 & 7 & 24.1 & - \\
\hline Thiazide or $\beta$-blocker & 13 & 10.3 & 8 & 8.2 & 5 & 29.0 & - \\
\hline$\beta$-blocker & 6 & 4.8 & 2 & 2.1 & 4 & 13.8 & 0.03 \\
\hline Thiazide & 9 & 7.1 & 6 & 6.2 & 3 & 10.3 & - \\
\hline Gemfibrozil & 1 & .8 & 1 & 1.0 & 0 & .0 & - \\
\hline Alcohol & $1 \dot{4}$ & 11.1 & 7 & 7.2 & 7 & 24.1 & 0.03 \\
\hline Tobacco & 5 & 4.0 & 3 & 3.1 & 2 & 6.9 & - \\
\hline
\end{tabular}

* Significance levels for prevalence differences between noncarriers and carriers were calculated by Fisher's Exact Test. ${ }^{\ddagger}$ Percentages are based on women only. Numerators indicate numbers of women receiving estrogens, and denominators, the total number of women in each group.

Table VI. Obesity and Related Factors in Carriers and Noncarriers Stratified by Age

\begin{tabular}{|c|c|c|c|c|c|}
\hline & \multicolumn{2}{|c|}{ Noncarriers* } & \multicolumn{2}{|c|}{ Carriers } & \multirow[t]{2}{*}{$P$ value ${ }^{\ddagger}$} \\
\hline & Mean & $S D$ & Mean & $S D$ & \\
\hline All subjects $(n=126)$ & \multicolumn{2}{|c|}{$n=96$} & \multicolumn{2}{|c|}{$n=29$} & \\
\hline Age $(y r)$ & 39.5 & 17.8 & 38.8 & 18.3 & - \\
\hline Systolic blood pressure $(\mathrm{mmHg})$ & 133 & 28 & 124 & 18 & - \\
\hline Diastolic blood pressure $(\mathrm{mmHg})$ & 80 & 16 & 77 & 11 & - \\
\hline Glucose $(m g / d l)$ & 94 & 16 & 93 & 42 & - \\
\hline Insulin $(\mu U / m l)$ & 14.2 & 9.9 & 13.8 & 11.7 & - \\
\hline Body mass index $\left(\mathrm{kg} / \mathrm{m}^{2}\right)$ & 26.2 & 6.8 & 26.7 & 7.2 & - \\
\hline Uric acid $(m g / d l)$ & 5.9 & 1.8 & 5.5 & 1.7 & - \\
\hline Age $<40$ yr $(n=71)$ & \multicolumn{2}{|c|}{$n=54$} & \multicolumn{2}{|c|}{$n=17$} & \\
\hline Age $(y r)$ & 25.3 & 9.6 & 26.9 & 9.6 & - \\
\hline Systolic blood pressure ( $\mathrm{mmHg}$ ) & 115 & 12 & 118 & 11 & - \\
\hline Diastolic blood pressure $(\mathrm{mmHg})$ & 72 & 9 & 71 & 10 & - \\
\hline Glucose $(m g / d l)$ & 86 & 28 & 86 & 10 & - \\
\hline Insulin $(\mu U / m l)$ & 11.4 & 10.6 & 10.9 & 7.2 & - \\
\hline Body mass index $\left(\mathrm{kg} / \mathrm{m}^{2}\right)$ & 24.0 & 6.4 & 22.2 & 4.3 & - \\
\hline Uric acid $(m g / d l)$ & 5.1 & 1.4 & 4.8 & 1.1 & - \\
\hline Age $\geq 40$ yr $(n=55)$ & \multicolumn{2}{|c|}{$n=42$} & \multicolumn{2}{|c|}{$n=12$} & \\
\hline Age $(y r)$ & 55.8 & 10.9 & 56.6 & 9.3 & - \\
\hline Systolic blood pressure $(\mathrm{mmHg})$ & 136 & 18 & 151 & 31 & - \\
\hline Diastolic blood pressure $(\mathrm{mmHg})$ & 83 & 9 & 89 & 15 & - \\
\hline Glucose $(m g / d l)$ & 102 & 53 & 104 & 17 & - \\
\hline Insulin $(\mu U / m l)$ & 16.8 & 12.5 & 18.3 & 11.5 & - \\
\hline Body mass index $\left(\mathrm{kg} / \mathrm{m}^{2}\right)$ & 30.4 & 6.5 & 31.5 & 5.6 & - \\
\hline Uric acid $(m g / d l)$ & 6.1 & 1.8 & 7.4 & 1.3 & 0.02 \\
\hline
\end{tabular}

* One insulin-treated diabetic subject (415) was excluded. ${ }^{\ddagger}$ Significance level determined by Mann-Whitney U corrected for ties. 
Table VII. Associated Factors in Hypertriglyceridemic and Normotriglyceridemic Subjects

\begin{tabular}{|c|c|c|c|c|c|}
\hline & \multicolumn{2}{|c|}{$\begin{array}{c}\text { Triglycerides } \\
<90 \text { th } \\
\text { percentile }\end{array}$} & \multicolumn{2}{|c|}{$\begin{array}{c}\text { Triglycerides } \\
\geq 90 \text { th } \\
\text { percentile }\end{array}$} & \multirow[t]{2}{*}{$P$ value } \\
\hline & Mean & $S D$ & Mean & $S D$ & \\
\hline Carriers (29) & \multicolumn{2}{|c|}{$n=20$} & \multicolumn{2}{|c|}{$n=20$} & \\
\hline Age $(y r)$ & 32.4 & 15.2 & 54.3 & 12.3 & 0.002 \\
\hline \multicolumn{6}{|l|}{ Systolic blood } \\
\hline pressure $(m m H g)$ & 121 & 16 & 155 & 32 & 0.003 \\
\hline \multicolumn{6}{|l|}{ Diastolic blood } \\
\hline pressure $(\mathrm{mmHg})$ & 72 & 11 & 94 & 13 & 0.001 \\
\hline Glucose $(m g / d l)$ & 91.1 & 17.6 & 99.3 & 9.7 & 0.03 \\
\hline Insulin $(\mu U / m l)$ & 11.1 & 6.4 & 20.7 & 12.8 & 0.03 \\
\hline \multicolumn{6}{|l|}{ Body mass index } \\
\hline$\left(\mathrm{kg} / \mathrm{m}^{2}\right)$ & 24.3 & 6.3 & 30.2 & 6.0 & 0.02 \\
\hline Uric acid $(m g / d l)$ & 5.2 & 1.6 & 7.3 & 1.3 & 0.002 \\
\hline Noncarriers (96) & \multicolumn{2}{|c|}{$n=84$} & \multicolumn{2}{|c|}{$n=12$} & \\
\hline Age (yr) & 38.2 & 18.6 & 42.8 & 16.6 & - \\
\hline \multicolumn{6}{|l|}{ Systolic blood } \\
\hline pressure $(\mathrm{mmHg})$ & 123 & 18 & 134 & 15 & 0.05 \\
\hline \multicolumn{6}{|l|}{ Diastolic blood } \\
\hline pressure $(m m H g)$ & 76 & 11 & 83 & 10 & 0.03 \\
\hline Glucose $(m g / d l)$ & 93.2 & 43.8 & 95.8 & 26.3 & - \\
\hline Insulin $(\mu U / m l)$ & 11.8 & 9.0 & 27.8 & 18.3 & $<0.001$ \\
\hline \multicolumn{6}{|l|}{ Body mass index } \\
\hline$\left(\mathrm{kg} / \mathrm{m}^{2}\right)$ & 26.1 & 6.9 & 31.1 & 8.1 & 0.03 \\
\hline Uric acid $(m g / d l)$ & 5.3 & 1.5 & 7.3 & 1.9 & $<0.001$ \\
\hline
\end{tabular}

* Levels of significance were determined by Mann-Whitney $U$ test corrected for ties after exclusion of data from subject 415 .

Obesity, hypertension, hyperuricemia, hyperinsulinemia, mild hyperglycemia, and low HDL were all observed in hypertriglyceridemic members of kindred 2003 who were thus representative of subjects with primary hypertriglyceridemia (27, 34-37). LPL activity (38-40) has correlated directly with plasma triglyceride concentration, inversely with in vivo measures of triglyceride disposal (39), and is affected by insulin (41-44), aging, and obesity $(38,39)$. In addition, a significant number of hyperlipidemic subjects were receiving estrogens, thiazides, and beta-adrenergic blocking drugs despite the wellknown propensity of these agents to perturb plasma lipid and lipoprotein metabolism.

Although techniques to study triglyceride kinetics have evolved significantly $(45,46)$, older studies clearly indicate that VLDL-TG production is highly correlated with body weight and fasting serum insulin concentration (47). Despite this prominent effect of obesity on VLDL production, maximum heparin-releasable plasma LPL activity fails to increase in obese normotriglyceridemic subjects (48). The complex interrelationships between hypertriglyceridemia and aging, obesity, insulin resistance, hyperinsulinemia, and carbohydrate intolerance have been studied intensively, yet a primary metabolic abnormality has not been accepted universally. There is experimental evidence that hyperfattyacidemia interferes with glucose disposal, increases plasma glucose concentrations, and thereby leads to hyperinsulinemia (49-52). Thus hyperinsulinemia in obesity (53) could be an epiphenomenon, rather than an independent determinant of VLDL-TG production rate $(54,55)$. Regardless of the underlying mechanism, heterozygous LPL deficiency and obesity would be expected to be cooperative in the pathogenesis of hypertriglyceridemia.

This study provides independent support for the proposal $(45,56,57)$ that a subset of patients with primary hypertriglyceridemia has an underlying inherited defect in triglyceride-rich lipoprotein removal consequent to impaired LPL function. Decreased LPL activity has been found in many (38, $39,58,59)$ but not all $(34,60)$ studies of patients with primary hypertriglyceridemia. Genetic defects in LPL, unrecognizable without specific probes for mutant alleles, might account for kinetic heterogeneity as well $(57,61)$. Decreased removal along with overproduction of VLDL has been observed in most

\section{Carriers}

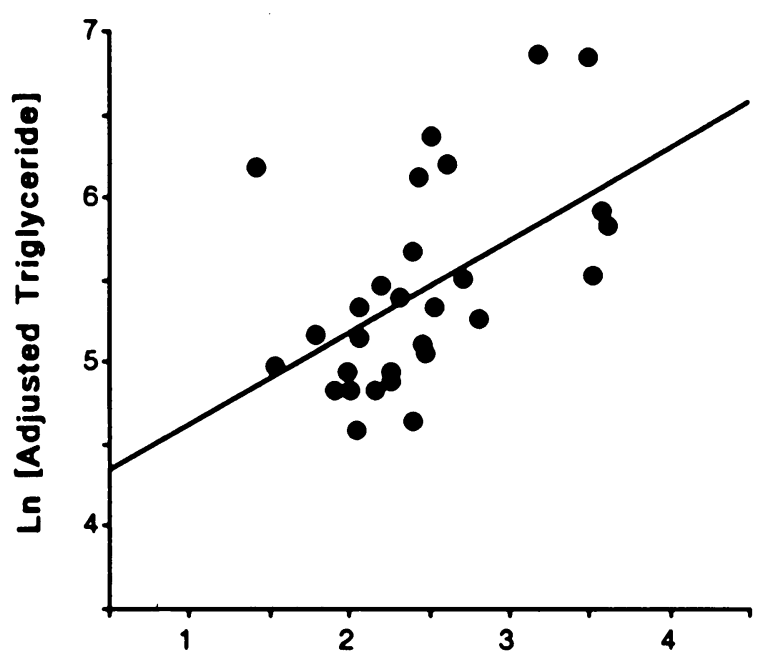

Non-Carriers

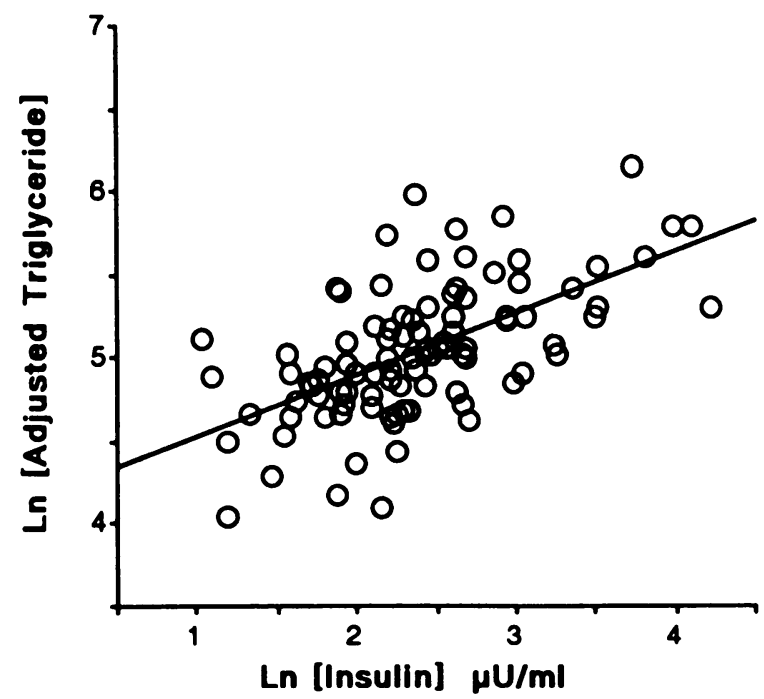

Figure 7. Linear regression of log-normalized plasma triglyceride concentration on log-normalized serum insulin in carriers and noncarriers. Pearson correlation coefficients for carriers $(r=0.51 ; P$ $=0.005 ; n=29)$ and noncarriers $(r=0.61 ; P=0.001 ; n=96)$ were calculated after exclusion of data from subject 415 . Other significant correlations existed between insulin- and log-triglyceride concentration and body mass index (see text). 
Table VIII. Multiple Linear Regression Analysis of Associated Conditions

\begin{tabular}{llcccc}
\hline & $\begin{array}{c}\text { Retained predictor } \\
\text { variables* }\end{array}$ & $p$ & $r$ & $F$ & $P$ value \\
\hline Ln (Systolic BP) & Age & 0.45 & & $<0.0001$ \\
& Body mass index & 0.28 & & & 0.0003 \\
& Age· Carrier status & 0.16 & & & 0.02 \\
& Sex & -0.14 & & & 0.03 \\
& All variables & & 0.72 & 30.8 & $<0.0001$ \\
& Age & 0.39 & & & $<0.0001$ \\
Ln (Diastolic BP) & Body mass index & 0.30 & & & 0.0006 \\
& All variables & & 0.61 & 34.4 & $<0.0001$ \\
& Thiazide use & 0.31 & & & 0.0003 \\
Ln (Glucose) & Sex & -0.19 & & & 0.02 \\
& $\beta$-Blockers & 0.17 & & & 0.04 \\
& All variables & & 0.44 & 9.7 & $<0.0001$ \\
& Body mass index & & 0.52 & 45.3 & $<0.0001$ \\
Ln (Insulin) & Body mass index & 0.36 & & & $<0.0001$ \\
Ln (Uric acid) & Sex & -0.34 & & $<0.0001$ \\
& Age & 0.20 & & 0.02 \\
& All variables & & 0.61 & 24.1 & $<0.0001$
\end{tabular}

* Numerical coding is defined in Table II, and other symbols in Table III. The predictor variables tested were age, sex, carrier status, age - carrier status, body mass index, and thiazide, estrogen, $\beta$ blocker, or alcohol use. When blood pressure was the dependent variable, thiazide and $\beta$-blocker use were omitted from analysis. Multivariate analysis was performed as described in the legend to Table III.

(61-68) but not all $(69,70)$ studies. Although obesity regularly leads to VLDL-TG overproduction, overweight subjects do not necessarily become hypertriglyceridemic if their TG clearance rates increase (62); other obese subjects without an increase in clearance become hypertriglyceridemic, consistent with heterogeneity in the efficiency of triglyceride catabolism.

Defective VLDL catabolism can be familial in subjects selected for primary hypertriglyceridemia. Thus, defective removal along with reduced postheparin LPL activity was found in older subjects with "poorly classified" familial hypertriglyceridemia (65). Sane and Nikkilä (68) found decreased FCR along with increased production in index subjects in whom coexisting defects in removal and production would be expected if overt hypertriglyceridemia requires increased lipoprotein synthesis. However, decreased FCR was the only ki-

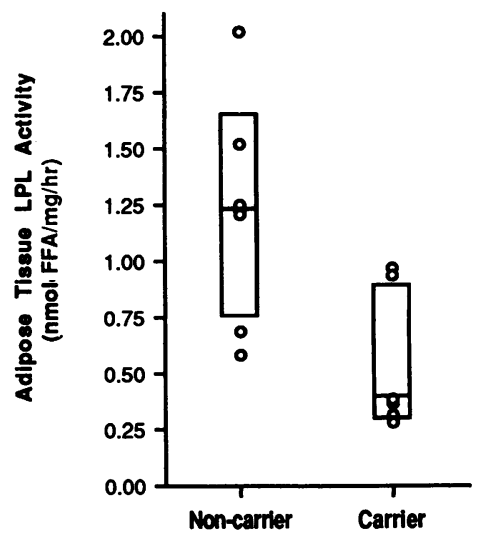

Figure 8. Adipose tissue LPL activities in seven carriers and seven noncarriers assayed previously in 1981 . The median and $95 \%$ confidence intervals are indicated.
Table IX. Prediction of Carrier Status in Subjects Aged $\geq 40$ yr by Discriminant Analysis

\begin{tabular}{|c|c|c|c|c|c|c|}
\hline \multirow{3}{*}{ Group } & \multicolumn{4}{|c|}{ Predicted } & & \\
\hline & \multicolumn{2}{|c|}{ Noncarriers } & \multicolumn{2}{|c|}{ Carriers } & \multicolumn{2}{|c|}{ Actual } \\
\hline & $n$ & $\%$ & $n$ & $\%$ & $n$ & $\%$ \\
\hline Carriers & 3 & 25.0 & 9 & 75.0 & 12 & 100 \\
\hline Noncarriers & 36 & 85.7 & 6 & 14.3 & 42 & 100 \\
\hline
\end{tabular}

Discriminant analysis was performed using carrier status as the grouping variable. The log-transformed discriminating variables, systolic blood pressure, diastolic blood pressure, uric acid, insulin, apo A-I, apo B, and age-sex adjusted triglyceride, VLDL cholesterol, LDL cholesterol, and HDL cholesterol, were included by a stepwise selection procedure with the smallest Wilks' lambda as the selection criterion. $F$-to-enter and $F$-to-remove were set at 3.5 and 2.5 , respectively. Default values were used for all other settings. The resulting discriminant function, which retained the predictor variables triglyceride, LDL cholesterol and apo B in the order mentioned, classified $83.3 \%$ of all analyzed cases correctly, assuming equal prior probability of belonging to either group.

netic abnormality segregating among the first-degree relatives of probands with a low VLDL-TG FCR (68).

Thus, our findings are consistent with the hypothesis that carriers become hypertriglyceridemic when VLDL production saturates $(71,72)$ the capacity of LPL to hydrolyze VLDL triglyceride; theoretically this can result from an increase in VLDL production, from LPL downregulation, or both. Such a mechanism might also explain why young homozygotes, with presumably normal or low rates of VLDL synthesis, have hyperchylomicronemia in the absence of elevated plasma VLDL (73), whereas older heterozygous carriers exhibit increased plasma VLDL concentrations.

Subjects with rare inherited metabolic disorders are often found to be compound heterozygotes at a molecular level (74). One must therefore anticipate pedigrees of LPL-deficient probands manifesting distinct allelic mutations, and others with clinically important interactions between mutant LPL genes and common non-allelic hyperlipidemia genes. Thus, if heterozygous LPL deficiency were to segregate independently along with a gene directing increased VLDL apo B synthesis, the phenotype observed in a pedigree might resemble familial combined hyperlipidemia. Whether other mutations in the LPL gene will result in clinically distinct phenotypes, or what the outcome will be of interactions of mutant LPL alleles with other more common hyperlipidemia genes remains to be investigated.

In summary, findings in this pedigree underscore the complex interactions between genetic and environmental factors that lead to hypertriglyceridemia. Heterozygosity for a mutation in the LPL gene was an important precondition for familial hypertriglyceridemia. Nevertheless, a number of noncarriers exhibited a nearly identical phenotype as they became older and heavier, and were exposed to lipid-raising drugs. Conversely, carriers of the mutant LPL allele remained normotriglyceridemic in the absence of these predisposing conditions. Since obesity, hyperinsulinemia, and the use of lipid-raising antihypertensive drugs and sex hormones are all reversible, the phenotype associated with heterozygous LPL-deficiency should be amenable to treatment. The present 
results do not exclude the possibility that interacting, yet-unidentified, genes affecting lipoprotein metabolism are influencing the observed phenotype. Indeed, it is expected that multiple gene-gene interactions will eventually be implicated which, together with mutant LPL alleles, will prove to be responsible for inherited, common-phenotype hypertriglyceridemias.

Heterozygous LPL deficiency usually led to a latent abnor- mality in lipoprotein metabolism which by itself, was neither necessary nor sufficient for the expression of familial hypertriglyceridemia. The frequency with which heterozygous LPL deficiency is a factor in the pathogenesis of familial hypertriglyceridemia is not known. These observations provide independent genetic evidence for the existence of a subset of hypertriglyceridemic subjects with combined defects in triglyceride metabolism $(56,61)$.

\section{Appendix}

Individual Data

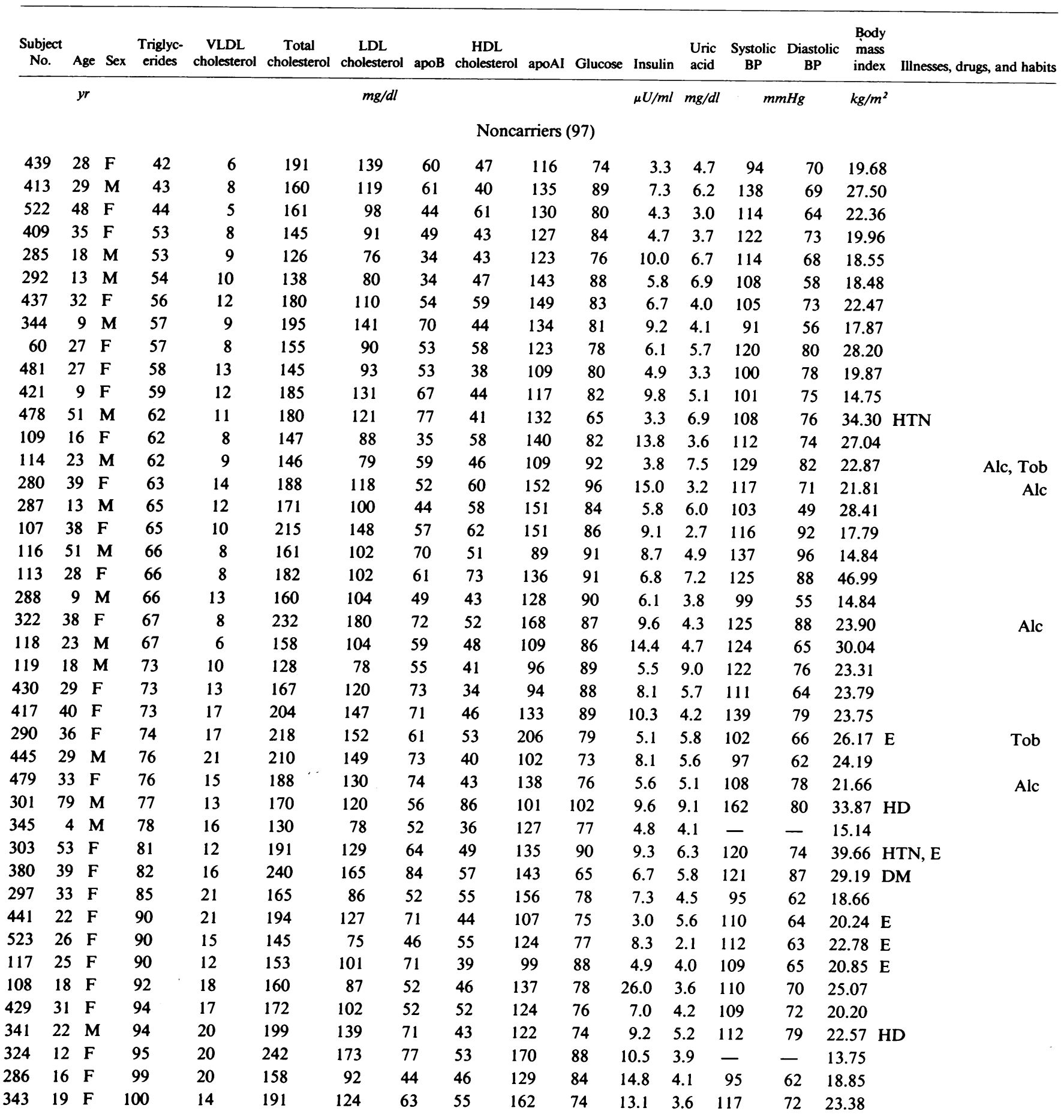

746 Wilson, Emi, Iverius, Hata, Wu, Hillas, Williams, and Lalouel 


\begin{tabular}{|c|c|c|c|c|c|c|c|c|c|c|c|c|c|c|c|c|}
\hline $\begin{array}{l}\text { Subject } \\
\text { No. }\end{array}$ & Age & Sex & $\begin{array}{l}\text { Triglyc- } \\
\text { erides }\end{array}$ & $\begin{array}{l}\text { VLDL } \\
\text { cholesterol }\end{array}$ & $\begin{array}{c}\text { Total } \\
\text { cholesterol }\end{array}$ & $\begin{array}{c}\text { LDL } \\
\text { cholesterol }\end{array}$ & apoB & $\begin{array}{c}\text { HDL } \\
\text { cholesterol }\end{array}$ & apoAI & Glucose & Insulin & $\begin{array}{l}\text { Uric } \\
\text { acid }\end{array}$ & $\begin{array}{c}\text { Systolic } \\
\text { BP }\end{array}$ & $\begin{array}{c}\text { Diastolic } \\
\text { BP }\end{array}$ & $\begin{array}{l}\text { Body } \\
\text { mass } \\
\text { index }\end{array}$ & Illnesses, drugs, and habits \\
\hline & $y r$ & & & & & $m g / d l$ & & & & & $\mu U / m l$ & $m g / d l$ & \multicolumn{2}{|c|}{$\mathrm{mmHg}$} & $\mathrm{kg} / \mathrm{m}^{2}$ & \\
\hline & \multicolumn{16}{|c|}{ Noncarriers (97) } \\
\hline 446 & 34 & $\mathbf{F}$ & 101 & 19 & 173 & 102 & 60 & 48 & 140 & 87 & 11.8 & 5.4 & 126 & 76 & 27.31 & DM, E \\
\hline 419 & 16 & $\mathbf{M}$ & 106 & 20 & 151 & 91 & 62 & 35 & 106 & 286 & 25.4 & 4.0 & 129 & 68 & 22.52 & DM \\
\hline 501 & 56 & $\mathbf{F}$ & 109 & 25 & 187 & 114 & 79 & 51 & 146 & 88 & 7.0 & 6.8 & 101 & 69 & 22.17 & $\mathbf{E}$ \\
\hline 283 & 42 & $\mathbf{F}$ & 114 & 21 & 176 & 99 & 49 & 57 & 166 & 89 & 8.9 & 3.9 & 122 & 72 & 26.19 & \\
\hline 30 & 53 & $\mathbf{F}$ & 116 & 16 & 204 & 97 & 68 & 86 & 196 & 99 & 21.1 & 4.5 & 120 & 103 & 38.39 & HTN, BpD, Tz, E \\
\hline 431 & 26 & $F$ & 118 & 26 & 179 & 101 & 62 & 52 & 140 & 78 & 6.6 & 4.2 & 108 & 74 & 18.88 & \\
\hline 174 & 66 & $\mathbf{M}$ & 123 & 23 & 236 & 166 & 95 & 47 & 126 & 117 & 10.8 & 6.3 & 139 & 83 & 26.25 & \\
\hline 135 & 34 & $\mathrm{~F}$ & 123 & 30 & 186 & 122 & 96 & 35 & 114 & 92 & 13.5 & 4.5 & 137 & 71 & 27.55 & \\
\hline 130 & 42 & $F$ & 123 & 31 & 198 & 118 & 80 & 50 & 129 & 88 & 11.6 & 4.6 & 134 & 80 & 26.27 & \\
\hline 299 & 20 & $\mathbf{F}$ & 123 & 24 & 145 & 73 & 53 & 51 & 178 & 83 & 9.0 & 4.6 & 111 & 72 & 19.22 & $\mathbf{E}$ \\
\hline 31 & 48 & $\mathbf{F}$ & 124 & 17 & 179 & 112 & 71 & 49 & 133 & 104 & 14.5 & 4.7 & 126 & 81 & 36.33 & HTN, BpD, Tz \\
\hline 415 & 69 & $\mathbf{M}$ & 124 & 33 & 228 & 155 & 100 & 41 & 131 & 194 & 253 & 7.0 & 126 & 74 & 21.13 & $\begin{array}{l}\text { HD, DM (insulin), } \\
\beta-B\end{array}$ \\
\hline 284 & 21 & $\mathrm{~F}$ & 125 & 25 & 161 & 86 & 50 & 50 & 174 & 78 & 2.8 & 3.9 & 104 & 62 & 18.36 & $\mathbf{E}$ \\
\hline 340 & 42 & $\mathbf{M}$ & 129 & 26 & 234 & 168 & 93 & 40 & 126 & 80 & 19.9 & 4.9 & 132 & 78 & 32.00 & HD \\
\hline 168 & 50 & $\mathbf{M}$ & 130 & 32 & 274 & 190 & 109 & 50 & 123 & 83 & 11.4 & 6.2 & 139 & 80 & 29.88 & Alc \\
\hline 418 & 38 & $\mathbf{F}$ & 132 & 21 & 176 & 115 & 69 & 36 & 112 & 84 & 11.0 & 4.6 & 127 & 78 & 33.94 & \\
\hline 138 & 20 & $\mathbf{M}$ & 132 & 19 & 172 & 107 & 64 & 42 & 116 & 97 & 9.1 & 6.2 & 128 & 78 & 19.82 & \\
\hline 393 & 58 & $\mathbf{F}$ & 138 & 30 & 241 & 167 & 74 & 42 & 118 & 106 & 14.8 & 6.7 & 146 & 79 & 31.82 & \\
\hline 333 & 34 & $\mathbf{F}$ & 140 & 29 & 168 & 108 & 78 & 30 & 98 & 80 & 13.6 & 5.9 & 132 & 58 & 32.05 & \\
\hline 477 & 51 & $\mathbf{F}$ & 143 & 31 & 227 & 142 & 83 & 43 & 142 & 96 & 12.8 & 6.9 & 138 & 86 & 22.12 & $\mathbf{E}$ \\
\hline 143 & 67 & $\mathbf{M}$ & 144 & 24 & 195 & 127 & 81 & 42 & 150 & 87 & 12.4 & 5.4 & 158 & 91 & 24.03 & HTN, Tz \\
\hline 407 & 58 & $\mathbf{M}$ & 148 & 38 & 250 & 180 & 93 & 30 & 101 & 100 & 11.3 & 6.2 & 122 & 105 & 26.58 & HTN, BpD \\
\hline 386 & 39 & $\mathbf{F}$ & 148 & 41 & 234 & 133 & 63 & 61 & 153 & 75 & 10.6 & 5.4 & 111 & 73 & 24.28 & \\
\hline 379 & 67 & $\mathbf{M}$ & 148 & 42 & 263 & 197 & 113 & 30 & 94 & 73 & 6.9 & 7.0 & 108 & 67 & 25.65 & HTN, BpD \\
\hline 342 & 20 & F & 148 & 28 & 225 & 164 & 120 & 40 & 158 & 80 & 10.0 & 4.6 & 132 & 81 & 21.66 & HTN, E \\
\hline 305 & 47 & $\mathbf{F}$ & 151 & 34 & 225 & 150 & 70 & 42 & 138 & 91 & 8.3 & 4.9 & 140 & 80 & 38.53 & \\
\hline 414 & 65 & $\mathrm{~F}$ & 164 & 35 & 234 & 142 & 85 & 52 & 155 & 93 & 9.9 & 8.1 & 152 & 84 & 30.15 & HTN \\
\hline 387 & 33 & $\mathbf{M}$ & 170 & 26 & 210 & 136 & 67 & 48 & 136 & 79 & 18.9 & 9.0 & 116 & 76 & 27.18 & \\
\hline 171 & 62 & $\mathbf{F}$ & 171 & 30 & 246 & 179 & 101 & 45 & 117 & 105 & 21.3 & 6.0 & 128 & 75 & 33.04 & HD \\
\hline 121 & 69 & $\mathbf{M}$ & 173 & 24 & 206 & 126 & 75 & 50 & 121 & 103 & 18.8 & 4.6 & 185 & 82 & 22.72 & HTN, BpD, Tz Alc \\
\hline 124 & 64 & $\mathbf{M}$ & 177 & 28 & 208 & 144 & 85 & 46 & 126 & 103 & 33.2 & 6.6 & 124 & 88 & 30.87 & \\
\hline 64 & 40 & $\mathbf{F}$ & 178 & 36 & 221 & 137 & 101 & 44 & 127 & 88 & 14.7 & 4.6 & 110 & 78 & 33.68 & \\
\hline 115 & 31 & $\mathbf{F}$ & 184 & 28 & 200 & 112 & 73 & 55 & 152 & 85 & 20.7 & 6.4 & 135 & 78 & 37.29 & $\begin{array}{r}\text { HTN, BpD, E } \\
\text { Alc }\end{array}$ \\
\hline 436 & 35 & $\mathbf{F}$ & 186 & 49 & 221 & 133 & 109 & 42 & 137 & 83 & 6.5 & 4.8 & 118 & 82 & 24.06 & HTN, BpD \\
\hline 63 & 39 & $\mathbf{M}$ & 188 & 30 & 170 & 118 & 58 & 31 & 100 & 84 & 68.6 & 6.2 & 139 & 86 & 38.99 & \\
\hline 173 & 60 & $\mathbf{M}$ & 189 & 31 & 200 & 129 & 82 & 32 & 101 & 421 & 33.6 & 3.6 & 147 & 88 & 32.43 & HTN, DM, BpD, Tz \\
\hline 165 & 58 & $\mathbf{F}$ & 191 & 24 & 195 & 100 & 55 & 71 & 168 & 93 & 11.5 & 5.0 & 144 & 73 & 35.30 & E \\
\hline 172 & 58 & $\mathbf{F}$ & 205 & 45 & 232 & 151 & 90 & 49 & 132 & 98 & 13.6 & 3.5 & 143 & 73 & 30.23 & $\mathbf{E}$ \\
\hline 378 & 64 & $\mathbf{F}$ & 207 & 37 & 235 & 122 & 66 & 79 & 203 & 94 & 13.9 & 7.0 & 140 & 87 & 27.28 & HTN, BpD, E \\
\hline 302 & 75 & $\mathbf{F}$ & 208 & 43 & 296 & 202 & 104 & 48 & 157 & 83 & 6.7 & 6.4 & 128 & 76 & 27.61 & \\
\hline 175 & 69 & $\mathbf{M}$ & 210 & 32 & 236 & 151 & 99 & 45 & 128 & 128 & 28.8 & 5.5 & 168 & 88 & 42.90 & \\
\hline 110 & 13 & $\mathbf{M}$ & 210 & 30 & 152 & 87 & 51 & 30 & 127 & 85 & 45.3 & 5.9 & 128 & 80 & 30.42 & \\
\hline 425 & 58 & $\mathbf{M}$ & 224 & 40 & 176 & 92 & 71 & 38 & 115 & 100 & 8.6 & 9.4 & 152 & 94 & 32.40 & Gout \\
\hline 176 & 80 & $\mathbf{M}$ & 238 & 46 & 215 & 127 & 70 & 33 & 83 & 101 & 17.6 & 5.9 & 159 & 85 & 25.52 & $\mathrm{HD}, \beta$-B \\
\hline 304 & 48 & $\mathbf{F}$ & 239 & 45 & 287 & 196 & 105 & 40 & 129 & 101 & 20.6 & 6.7 & 152 & 104 & 44.39 & \\
\hline 435 & 37 & $\mathbf{M}$ & 251 & 53 & 204 & 116 & 79 & 34 & 109 & 87 & 11.5 & 7.3 & 116 & 75 & 30.57 & HTN \\
\hline 166 & 68 & $\mathbf{M}$ & 257 & 80 & 227 & 112 & 78 & 32 & 107 & 32 & 14.6 & 6.9 & 134 & 80 & 28.20 & \\
\hline 416 & 41 & $\mathbf{M}$ & 258 & 47 & 150 & 68 & 71 & 30 & 115 & 112 & 33.4 & 8.7 & 159 & 84 & 35.69 & HTN, BpD \\
\hline 420 & 12 & $\mathbf{M}$ & 282 & 44 & 133 & 61 & 61 & 28 & 112 & 83 & 18.7 & 6.0 & 114 & 67 & 25.69 & \\
\hline 389 & 44 & $\mathbf{F}$ & 286 & 66 & 253 & 155 & 93 & 34 & 128 & 98 & 13.8 & 4.7 & 128 & 96 & 23.89 & \\
\hline 131 & 41 & $\mathbf{F}$ & 291 & 59 & 246 & 153 & 95 & 42 & 147 & 99 & 53.9 & 6.7 & 132 & 87 & 33.26 & HTN \\
\hline 385 & 57 & $\mathbf{F}$ & 301 & 66 & 284 & 167 & 110 & 52 & 169 & 86 & 8.9 & 8.0 & 140 & 83 & 21.33 & HTN, HD, BpD, E \\
\hline
\end{tabular}




\begin{tabular}{|c|c|c|c|c|c|c|c|c|c|c|c|c|c|c|c|c|}
\hline $\begin{array}{l}\text { Subject } \\
\text { No. }\end{array}$ & Age & Sex & $\begin{array}{l}\text { Triglyc- } \\
\text { erides }\end{array}$ & $\begin{array}{l}\text { VLDL } \\
\text { cholesterol }\end{array}$ & $\begin{array}{c}\text { Total } \\
\text { cholesterol }\end{array}$ & $\begin{array}{c}\text { LDL } \\
\text { cholesterol }\end{array}$ & apoB & $\begin{array}{c}\text { HDL } \\
\text { cholesterol }\end{array}$ & apoAI & Glucose & Insulin & $\begin{array}{l}\text { Uric } \\
\text { acid }\end{array}$ & $\begin{array}{l}\text { Systolic } \\
\text { BP }\end{array}$ & $\begin{array}{l}\text { Diastolic } \\
\text { BP }\end{array}$ & $\begin{array}{l}\text { Body } \\
\text { mass } \\
\text { index }\end{array}$ & Illnesses, drugs, and habits \\
\hline & $y r$ & & & & & $m g / d l$ & & & & & $\mu U / m l$ & $m g / d l$ & & $m H g$ & $\mathrm{~kg} / \mathrm{m}^{2}$ & \\
\hline \multicolumn{17}{|c|}{ Noncarriers (97) } \\
\hline 136 & 58 & $\mathbf{M}$ & 320 & 43 & 251 & 168 & 122 & 30 & 94 & 144 & 60.4 & 6.7 & 143 & 77 & 27.531 & DM \\
\hline 123 & 44 & $\mathbf{M}$ & 398 & 102 & 267 & 131 & 92 & 28 & 119 & 82 & 10.7 & 7.4 & 118 & 82 & 24.77 & 1 \\
\hline 13 & 51 & $\mathbf{F}$ & 452 & 92 & 281 & 149 & 145 & 34 & 131 & 114 & 41.8 & 12.2 & - & - & 47.621 & HTN, BpD, Tz \\
\hline \multicolumn{17}{|c|}{ Carriers (29) } \\
\hline 281 & 17 & $\mathrm{~F}$ & 43 & 10 & 165 & 119 & 53 & 44 & 125 & 73 & 11.1 & 4.0 & - & - & - & \\
\hline 145 & 38 & $\mathrm{~F}$ & 56 & 9 & 211 & 144 & 80 & 56 & 146 & 77 & 7.8 & 4.1 & 102 & 67 & 21.08 & \\
\hline 332 & 32 & $\mathbf{F}$ & 73 & 15 & 183 & 120 & 53 & 53 & 123 & 74 & 8.8 & 4.3 & 112 & 54 & 23.96 & \\
\hline 291 & 16 & F & 79 & 14 & 149 & 97 & 45 & 39 & 150 & 79 & 9.7 & 5.0 & 104 & 56 & 17.99 & Alc, Tob \\
\hline 127 & 35 & F & 83 & 22 & 191 & 138 & 75 & 43 & 115 & 91 & 6.8 & 5.8 & 132 & 88 & 25.55 & \\
\hline 282 & 11 & $\mathrm{~F}$ & 84 & 12 & 179 & 126 & 43 & 134 & 92 & 7.4 & 3.4 & - & - & 14.46 & & \\
\hline & & & & & & F 55 & & & & & & & & & & \\
\hline 323 & 16 & $\mathbf{M}$ & 90 & 18 & 205 & 144 & 67 & 45 & 145 & 92 & 4.7 & 5.5 & 117 & 75 & 19.30 & \\
\hline 300 & 8 & $\mathbf{F}$ & 104 & 15 & 183 & 125 & 63 & 42 & 129 & 94 & 8.0 & 3.1 & - & - & 15.70 & \\
\hline 146 & 31 & $\mathrm{~F}$ & 104 & 19 & 167 & 100 & 69 & 48 & 127 & 92 & 12.1 & 3.5 & 127 & 68 & 20.91 & \\
\hline 125 & 37 & $\mathbf{M}$ & 110 & 26 & 247 & 172 & 75 & 61 & 115 & 85 & 7.5 & 4.8 & 116 & 75 & 23.51 & Alc \\
\hline 331 & 26 & $\mathrm{~F}$ & 118 & 32 & 180 & 115 & 63 & 28 & 87 & 80 & 11.9 & 5.7 & 128 & 69 & 31.91 & \\
\hline 126 & 42 & $\mathbf{M}$ & 131 & 23 & 221 & 157 & 79 & 41 & 139 & 93 & 9.7 & 5.6 & 116 & 72 & 28.00 & Alc \\
\hline 128 & 30 & $F$ & 156 & 26 & 198 & 139 & 85 & 36 & 112 & 94 & 7.9 & 5.2 & 120 & 75 & 26.25 & Alc \\
\hline 134 & 35 & $\mathbf{M}$ & 161 & 30 & 216 & 148 & 75 & 38 & 124 & 99 & 6.0 & 5.5 & 132 & 68 & 22.71 & \\
\hline 62 & 35 & $\mathbf{F}$ & 167 & 25 & 193 & 123 & 93 & 40 & 116 & 89 & 12.9 & 3.2 & 115 & 87 & 19.96 & E \\
\hline 3 & 59 & $\mathbf{M}$ & 184 & 32 & 167 & 101 & 91 & 37 & 119 & 149 & 16.9 & 9.2 & 168 & 99 & 36.61 & $\begin{array}{l}\text { HTN, DM, BpD, } \\
\quad \beta-\mathrm{B}, \mathrm{Tz}\end{array}$ \\
\hline 298 & 30 & $\mathbf{M}$ & 195 & 42 & 128 & 55 & 57 & 24 & 92 & 88 & 10.3 & 7.2 & 118 & 65 & 24.95 & \\
\hline 388 & 28 & $\mathbf{F}$ & 197 & 40 & 192 & 99 & 58 & 49 & 140 & 66 & 15.4 & 5.6 & 99 & 63 & 23.41 & $\mathrm{E}$ \\
\hline 384 & 61 & $\mathbf{F}$ & 215 & 50 & 251 & 168 & 96 & 34 & 120 & 115 & 9.1 & 7.9 & 112 & 71 & 28.04 & HTN, DM, BpD \\
\hline 167 & 61 & $\mathrm{~F}$ & 229 & 91 & 359 & 224 & 117 & 40 & 152 & 100 & 34.4 & 6.1 & 139 & 69 & 38.17 & \\
\hline 142 & 63 & $\mathbf{F}$ & 268 & 61 & 233 & 97 & 87 & 68 & 189 & 89 & 11.1 & 6.0 & 210 & 90 & 28.76 & HTN, BpD, $\beta$-B, E \\
\hline 11 & 64 & $\mathbf{F}$ & 317 & 62 & 186 & 104 & 84 & 28 & 111 & 113 & 38.1 & 8.7 & 144 & 92 & 40.75 & $\begin{array}{c}\text { HTN, HtD, gout, } \\
\text { BpD, } \beta-B, T z\end{array}$ \\
\hline 61 & 33 & $\mathbf{M}$ & 348 & 49 & 161 & 79 & 71 & 28 & 101 & 103 & 36.7 & 5.8 & 128 & 80 & 24.09 & \\
\hline 12 & 62 & $\mathbf{M}$ & 442 & 111 & 249 & 88 & 113 & 39 & 105 & 101 & 11.5 & 6.8 & 172 & 111 & 32.59 & HTN \\
\hline 122 & 40 & $\mathbf{M}$ & 478 & 86 & 211 & 78 & 75 & 36 & 121 & 107 & 4.2 & 7.8 & 114 & 72 & 22.50 & Alc, Tob \\
\hline 10 & 68 & $\mathbf{F}$ & 483 & 146 & 263 & 86 & 125 & 30 & 151 & 98 & 13.9 & 6.6 & 197 & 112 & 25.16 & HTN, BpD, Tz, E \\
\hline 390 & 44 & $\mathbf{M}$ & 575 & 105 & 215 & 85 & 89 & 25 & 113 & 80 & 12.5 & 9.8 & 142 & 99 & 28.08 & HTN, BpD \\
\hline 2 & 59 & $\mathbf{F}$ & 916 & 102 & 354 & 119 & 191 & 30 & 127 & 100 & 33.8 & 7.7 & 140 & 99 & 36.21 & HTN, BpD, $\beta$-B \\
\hline 169 & 56 & $\mathbf{M}$ & 936 & 154 & 338 & 117 & 94 & 28 & 123 & 103 & 24.7 & 6.8 & 152 & 87 & 33.46 & Alc \\
\hline
\end{tabular}

Clinical variables in the 126 study subjects classified by genotype and sorted in order of ascending plasma triglyceride concentration. Subject number, age, sex, triglyceride, VLDL cholesterol, total plasma cholesterol, LDL cholesterol, apoB, HDL cholesterol, apoA-I, glucose, insulin, number, age, sex, triglyceride, sion; HtD, heart disease; DM, diabetes mellitus; $\mathrm{BpD}$, antihypertensive drugs of any kind; $\beta$-B, beta-adrenergic blockers; Tz, benzothiadiazides; E, estrogens; Alc, alcohol; and Tob, tobacco use. Subjects whose age- and sex-adjusted triglyceride concentrations exceed the 90th percentile cutpoint from the Lipid Research Clinics database are indicated by boldface type.

\section{Acknowledgments}

This work was supported in part by National Institutes of Health grants HL-39595, RR-00064 to the Clinical Research Center and HL-21088, by the Nora Eccles Treadwell Foundation and the Veterans Administration. J.-M. Lalouel is an Investigator at the Howard Hughes Medical Institute.

\section{References}

1. Brunzell, J. D. 1989. Familial lipoprotein lipase deficiency and other causes of the chylomicronemia syndrome. In The Metabolic Basis of Inherited Disease. C. R. Scriver, A. L. Beaudet, W. S. Sly, and D. Valle, editors. 6th ed. McGraw-Hill Book Co., New York. 1165-1180. 
2. Nikkilä, E. A. 1983. Familial lipoprotein lipase deficiency and related disorders of chylomicron metabolism. In The Metabolic Basis of Inherited Disease. J. B. Stanbury, J. B. Wyngaarden, D. S. Fredrickson, J. L. Goldstein, and M. S. Brown, editors. 5th ed. McGrawHill Book Co., New York. 622-642.

3. Lees, R. S., D. E. Wilson, G. Schoenfeld, and S. Fleet. 1973. The familial dyslipoproteinemias. Prog. Med. Genet. 9:237-290.

4. Breckenridge, W. C., J. A. Little, G. Steiner, A. Chow, and M. Poapst. 1978. Hypertriglyceridemia associated with deficiency of apolipoprotein C-II. $N$. Engl. J. Med. 298:1265-1273.

5. Harlan, W. R., Jr., P. S. Winesett, and A. J. Wasserman. 1967. Tissue lipoprotein lipase in normal individuals and in individuals with exogenous hypertriglyceridemia and the relationship of this enzyme to assimilation of fat. J. Clin. Invest. 46:239-247.

6. Babirak, S. P., P-H. Iverius, W. Y. Fujimoto, and J. D. Brunzell. 1989. Detection and characterization of the heterozygote state for lipoprotein lipase deficiency. Arteriosclerosis. 9:326-334.

7. Wilson, D. E., C. Q. Edwards, and I-F. Chan. 1983. Phenotypic heterogeneity in the extended pedigree of a proband with lipoprotein lipase deficiency. Metab. Clin. Exp. 32:1107-1114.

8. Fellin, R., G. Baggio, A. Poli, J. Augustin, M. R. Baiocchi, G. Baldo, M. Sinigaglia, H. Greten, and G. Crepaldi. 1983. Familial lipoprotein lipase and apolipoprotein C-II deficiency. Atherosclerosis. 49:55-68.

9. Berger, G. M. B., and F. Bonnici. 1977. Familial hyperchylomicronemia in four families. S. Afr. Med. J. 51:623-628.

10. Gagné, C., D. Brun, S. Moorjani, and P-J. Lupien. 1977. Hyperchylomicronémie familiale: étude de l'activité lipolytique dans une famille. Union Med. Can. 106:333-338.

11. Goldstein, J. L., H. G. Schrott, W. R. Hazzard, E. L. Bierman, and A. G. Motulsky. 1973. Hyperlipidemia in coronary heart disease. II. Genetic analysis of lipid levels in 176 families and delineation of a new inherited disorder, combined hyperlipidemia. J. Clin. Invest. 52:1544-1568.

12. Brunzell, J. D., P-H. Iverius, M. S. Scheibel, W. Y. Fujimoto, M. R. Hayden, R. McLeod, and J. Frölich. 1986. Primary lipoprotein lipase deficiency. In Lipoprotein Deficiency Syndromes. A. Angel and J. Frölich, editors. Plenum Publishing Corp., New York. pp. 227-239.

13. Auwerx, J. H., S. P. Babirak, W. Y. Fujimoto, P-H. Iverius, and J. D. Brunzell. 1989. Defective enzyme protein in lipoprotein lipase deficiency. Eur. J. Clin. Invest. 19:433-437.

14. Scheibel, M. S., P-H. Iverius, J. D. Brunzell, J. H. Auwerx, and W. Y. Fujimoto. 1985. An enzyme linked immunosorbent assay for nondenatured human lipoprotein lipase. Fed. Proc. 43:1156a.(Abstr.)

15. Wion, L., T. G. Kirchgessner, A. J. Lusis, M. C. Schotz, and R. M. Lawn. 1987. Human lipoprotein lipase complementary DNA sequence. Science (Wash. DC). 235:1638-1641.

16. Deeb, S. S., and R. Peng. 1989. Structure of the human lipoprotein lipase gene. Biochemistry. 28:4131-4135.

17. Langlois, S., S. Deeb, J. D. Brunzell, J. J. Kastelein, and M. R. Hayden. 1989. A major insertion accounts for a significant proportion of mutations underlying human lipoprotein lipase deficiency. Proc. Natl. Acad. Sci. USA. 86:948-952.

18. Emi, M., D. E. Wilson, P-H. Iverius, L. Wu, A. Hata, R. Hegele, R. R. Williams, and J-M. Lalouel. 1990. Missense mutation (Gly $\rightarrow$ $\mathrm{Glu}_{188}$ ) of human lipoprotein lipase imparting functional deficiency. $J$. Biol. Chem. 265:5910-5916.

19. Lipid Research Clinics Program. 1974. Manual of Laboratory Operations. Department of Health, Education, and Welfare (National Institutes of Health) Publ. No. 75-628.

20. Wu, L. L., G. R. Warnick, J. T. Wu, R. R. Williams, and J-M. Lalouel. 1989. A rapid micro-scale procedure for determination of the total lipid profile. Clin. Chem. 35:1486-1491.

21. Warnick, G. R., J. Benderson, and J. J. Albers. 1982. Dextran sulfate- $\mathrm{Mg}^{2+}$ precipitation procedure for quantitation of high-densitylipoprotein cholesterol. Clin. Chem. 28:1379-1388.

22. Siegel, S. 1956. Nonparametric Statistics for the Behavioral Sciences. McGraw-Hill Book Co., New York. 312 pp.
23. Dixon, W. J., and F. J. Massey, Jr. 1969. Introduction to Statistical Analysis. 3rd ed. McGraw-Hill Book Co., New York. 638 pp.

24. Lipid Research Clinics Population Studies Data Book. 1980. Volume I. The Prevalence Study. United States Department of Health and Human Services (Public Health Service). National Institutes of Health Publ. No. 80-1527.

25. Fredrickson, D. S., and R. I. Levy. 1972. Familial hyperlipoproteinemia. In The Metabolic Basis of Inherited Disease. J. B. Stanbury, J. B. Wyngaarden, and D. S. Fredrickson, editors. 3rd ed. McGraw-Hill Book Co., New York. 592-604.

26. Greenfield, M. S., F. Kraemer, and G. Reaven. 1980. Effect of age on plasma triglyceride concentrations in man. Metab. Clin. Exp. 29:1095-1099.

27. Fredrickson, D. S., R. I. Levy, and R. S. Lees. 1967. Fat transport in lipoproteins: an integrated approach to mechanisms and disorders. N. Engl. J. Med. 276:34-44, 94-103, 148-156, 215-227, 273-281.

28. Modan, M., H. Halkin, A. Lusky, P. Segal, F. Fuchs, and A. Chetrit. 1988. Hyperinsulinemia is characterized by jointly disturbed plasma VLDL, LDL, and HDL levels. Arteriosclerosis. 8:227-236.

29. Nikkilä, E. A., M-R. Taskinen, and T. Sane. 1987. Plasma high-density lipoprotein concentration and subfraction distribution in relation to triglyceride metabolism. Am. Heart J. 113:543-548.

30. Kekki, M. 1980. Lipoprotein-lipase action determining plasma high density lipoprotein cholesterol level in adult normolipaemics. Atherosclerosis. 37:143-150.

31. Saku, K., P. S. Gartside, B. A. Hynd, S. G. Mendoza, and M. L. Kashyap. 1985. Apolipoprotein AI and AII metabolism in patients with primary high-density lipoprotein deficiency associated with familial hypertriglyceridemia. Metab. Clin. Exp. 34:754-764.

32. Kuusi, T., C. Ehnholm, J. Viikari, R. Härkönen, E. Vartiainen, P. Puska, and M-R. Taskinen. 1989. Postheparin plasma lipoprotein and hepatic lipase are determinants of hypo- and hyperalphalipoproteinemia. J. Lipid Res. 30:1117-1126.

33. Minnich, A., B. G. Nordestgaard, and D. B. Zilversmit. 1989. A novel explanation for the reduced LDL cholesterol in severe hypertriglyceridemia. J. Lipid Res. 30:347-355.

34. Krauss, R. M., R. I. Levy, and D. S. Fredrickson. 1974. Selective measurement of two lipase activities in postheparin plasma from normal subjects and patients with hyperlipoproteinemia. J. Clin. Invest. 54:1107-1124.

35. Goldstein, J. L., W. R. Hazzard, H. G. Schrott, E. L. Bierman, and A. G. Motulsky. 1973. Hyperlipidemia in coronary heart disease. I. Lipid levels in $\mathbf{5 0 0}$ survivors of myocardial infarction. J. Clin. Invest. 52:1533-1543.

36. Glueck, C. J., R. I. Levy, and D. S. Fredrickson. 1969. Immunoreactive insulin, glucose tolerance, and carbohydrate inducibility in Types II, II, IV, and V hyperlipoproteinemia. Diabetes. 18:739-747.

37. Greenberg, B. H., W. C. Blackwelder, and R. I. Levy. 1977. Primary type $\mathrm{V}$ hyperlipoproteinemia. A descriptive study in 32 families. Ann. Int. Med. 87:526-534.

38. Persson, B. 1973. Lipoprotein lipase activity of human adipose tissue in different types of hyperlipidemia. Acta Med. Scand. 193:447456.

39. Huttunen, J. K., C. Ehnholm, M. Kekki, and E. A. Nikkilä. 1976. Post-heparin plasma lipoprotein lipase and hepatic lipase in normal subjects and patients with hypertriglyceridaemia: correlations to sex, age and various parameters of triglyceride metabolism. Clin. Sci. Mol. Med. 50:249-260.

40. Huttunen, J. K., C. Ehnholm, E. A. Nikkilä, and M. Ohta. 1975. Effect of fasting on two postheparin plasma triglyceride lipases and triglyceride removal in obese subjects. Eur. J. Clin. Invest. 5:435445 .

41. Nikkilä, E. A., J. K. Huttunen, and C. Ehnholm. 1977. Postheparin plasma lipoprotein lipase and hepatic lipase in diabetes mellitus. Diabetes. 26:11-21.

42. Kessler, J. I. 1963. Effect of diabetes and insulin on the activity 
of myocardial and adipose tissue lipoprotein lipase. J. Clin. Invest. 42:362-367.

43. Wilson, D. E., R. Zeikus, and I-F. Chan. 1987. Relationship of organ lipoprotein lipase activity and ketonuria to hypertriglyceridemia in starved and streptozocin-induced diabetic rats. Diabetes. 36:485490.

44. Ong, J. M., T. G. Kirchgessner, M. C. Schotz, and P. A. Kern. 1988. Insulin increases the synthetic rate and messenger RNA level of lipoprotein lipase in isolated rat adipocytes. J. Biol. Chem. 263:12933-12938.

45. Nikkilä, E. A., and M. Kekki. 1973. Plasma triglyceride transport kinetics in diabetes mellitus. Metab. Clin. Exp. 22:1-22.

46. Zech, L. A., S. M. Grundy, D. Steinberg, and M. Berman. 1979. Kinetic model for production and metabolism of very low density lipoprotein triglycerides. J. Clin. Invest. 63:1262-1273.

47. Eaton, R. P., and W. H. R. Nye. 1973. The relationship between insulin secretion and triglyceride concentration in endogenous lipemia. J. Lab. Clin. Med. 81:682-695.

48. Wilson, D. E., B. W. Glad, P. K. Working, and M. E. Adler. 1978. Postheparin plasma lipase activities in obesity: failure to increase with adipose organ enlargement. Metab. Clin. Exp. 27:1084-1094.

49. Thiébaud, D., R. A. DeFronzo, E. Jacot, A. Golay, K. Acheson, E. Maeder, E. Jéquier, and J-P Felber. 1982. Effect of long chain triglyceride infusion on glucose metabolism in man. Metab. Clin. Exp. 31:1128-1136.

50. Ferrannini, E., E. J. Barrett, S. Bevilacqua, and R. A. DeFronzo. 1983. Effect of fatty acids on glucose production and utilization in man. J. Clin. Invest. 72:1737-1747.

51. Meylan, M., C. Henny, E. Temier, E. Jéquier, and J. P. Felber 1987. Metabolic factors in the insulin resistance in human obesity. Metab. Clin. Exp. 36:256-261.

52. Bevilacqua, S., R. Bonnadonna, G. Buzzigoli, C. Boni, D. Ciociaro, F. Maccari, M. A. Giorco, and E. Ferrannini. 1987. Acute elevation of free fatty acid levels leads to hepatic insulin resistance in obese subjects. Metab. Clin. Exp. 36:502-506.

53. Berson, S. A., and R. S. Yalow. 1965. Some current controversies in diabetes research. Diabetes. 14:549-572.

54. Olefsky, J. M., J. W. Farquhar, and G. M. Reaven. 1974. Reappraisal of the role of insulin in hypertriglyceridemia. Am. J. Med. 57:551-560.

55. Reaven, G. M., R. L. Lerner, M. P. Stern, and J. W. Farquhar. 1967. Role of insulin in endogenous hypertriglyceridemia. J. Clin. Invest. 46:1756-1767.

56. Grundy, S. M. 1984. Pathogenesis of hyperlipoproteinemia. $J$. Lipid Res. 25:1611-1618.

57. Grundy, S. M., and G. L. Vega. 1988. Hypertriglyceridemia: causes and relation to coronary heart disease. Sem. Thromb. Hemostasis. 14:149-164.

58. Taylor, K. G., G. Holdsworth, D. J. Galton. 1980. Lipoprotein lipase in adipose tissue and plasma triglyceride clearance in patients with primary hypertriglyceridaemia. Eur. J. Clin. Invest. 10:133-138.

59. Taskinen, R-R., E. A. Nikkilä, and T. Kuusi. 1982. Lipoprotein lipase activity of adipose tissue, skeletal muscle and post-heparin plasma in primary endogenous hypertriglyceridaemia: relationship to lipoprotein pattern and to obesity. Eur. J. Clin. Invest. 12:433-438.
60. Goldberg, A. P., A. Chait, and J. D. Brunzell. 1980. Postprandial adipose tissue lipoprotein lipase activity in primary hypertriglyceridemia. Metab. Clin. Exp. 29:223-229.

61. Kesaniemi, A., and S. M. Grundy. 1984. Dual defect in metabolism of very-low-density lipoprotein triglycerides. Patients with Type 5 hyperlipoproteinemia. JAMA (J. Am. Med. Assoc.). 251:2542-2547.

62. Grundy, S. M., H. Y. I. Mok, L. Zech, D. Steinberg, and M. Berman. 1979. Transport of very low density lipoprotein triglycerides in varying degrees of obesity. J. Clin. Invest. 63:1274-1283.

63. Packard, C. J., J. Shepherd, S. Joerns, A. M. Gotto Jr., and O. D. Taunton. 1980. Apolipoprotein B metabolism in normal, Type IV, and Type V hyperlipoproteinemic subjects. Metab. Clin. Exp. 29:213-222.

64. Janus, E. D., A. M. Nicoll, P. R. Turner, P. Magill, and B. Lewis. 1980. Kinetic bases of the primary hyperlipidaemias: studies of apolipoprotein B turnover in genetically defined subjects. Eur. J. Clin. Invest. 10:161-172.

65. Beil, U., S. M. Grundy, J. R. Crouse, and L. Zech. 1982. Triglyceride and cholesterol metabolism in primary hypertriglyceridemia. Arteriosclerosis. 2:44-57.

66. Stalenhoef, A. F. H., P. N. M. Demacker, J. A. Lutterman, and A. van't Laar. 1986. Plasma lipoproteins, apolipoproteins, and triglyceride metabolism in familial hypertriglyceridemia. Arteriosclerosis. 6:387-394.

67. Dunn, F. L., S. M. Grundy, D. W. Bilheimer, R. J. Havel, and P. Raskin. 1985. Impaired catabolism of very low-density lipoproteintriglyceride in a family with primary hypertriglyceridemia. Metab. Clin. Exp. 34:316-324.

68. Sane, T., and E. A. Nikkilä. 1988. Very low density lipoprotein triglyceride metabolism in relatives of hypertriglyceridemic probands. Evidence for genetic control of triglyceride removal. Arteriosclerosis. 8:217-226.

69. Chait, A., J. J. Albers, and J. D. Brunzell. 1980. Very low density lipoprotein overproduction in genetic forms of hypertriglyceridaemia. Eur. J. Clin. Invest. 10:17-22.

70. Kissebah, A. H., S. Alfarsi, and P. W. Adams. 1981. Integrated regulation of very low density lipoprotein triglyceride and apolipoprotein-B kinetics in man: normolipemic subjects, familial hypertriglyceridemia and familial combined hyperlipidemia. Metab. Clin. Exp. 30:856-868.

71. Reaven, G. M., D. B. Hill, R. C. Gross, and J. W. Farquhar. 1965. Kinetics of triglyceride turnover of very low density lipoproteins of human plasma. J. Clin. Invest. 44:1826-1833.

72. Brunzell, J. D., W. R. Hazzard, D. Porte, Jr., and E. L. Bierman. 1973. Evidence for a common, saturable, triglyceride removal mechanism for chylomicrons and very low density lipoproteins in man. J. Clin. Invest. 52:1578-1585.

73. Lees, R. S., and D. S. Fredrickson. 1965. The differentiation of exogenous and endogenous hyperlipemia by paper electrophoresis. $J$. Clin. Invest. 44:1968-1977.

74. Beaudet, A. L., C. R. Scriver, W. S. Sly, D. Valle, D. N. Cooper, V. A. McKusick, and J. Schmidke. 1989. Genetics and biochemistry of variant human phenotypes. In The Metabolic Basis of Inherited Disease. C. R. Scriver, A. L. Beaudet, W. S. Sly, and D. Valle, editors. 6th edition. McGraw-Hill Book Co., New York. 28-30. 